\title{
A Political Agency Theory of Central Bank Independence
}

\author{
Gauti Eggertsson and Eric Le Borgne ${ }^{1}$ \\ $\mathrm{IMF}$
}

October 2004

(first version July 2003)

\begin{abstract}
We propose a theory to explain why, and under what circumstances, a politician endogenously gives up rent and delegates policy tasks to an independent agency. We apply this theory to monetary policy by extending a stochastic general equilibrium model. This model provides a theory of central bank independence that is unrelated to the standard time inconsistency problem which underlies all formalized theories of central bank independence. We derive five key predictions of the model and show that they are broadly consistent with the data. Finally, we show that while instrument independence of the central bank is desirable, goal independence is not.
\end{abstract}

Keywords: Central Bank Independence, Elections, Career Concerns, Learning-by-doing. JEL Classification Numbers: E58, E61, H11, J45.

\footnotetext{
${ }^{1}$ For helpful discussions and suggestions, we would like to thank Tam Bayoumi, Xavier Debrun, Olivier Jeanne, Lars Svensson, Ken Rogoff, Philip Schellekens, Jeromin Zettelmeyer, and seminar participants at the Bank of England, the IMF, and the European Economic Association annual conference. The usual disclaimer applies. Corresponding author: Eric Le Borgne, Fiscal Affairs Department (TPD), International Monetary Fund, 700 19th Street NW, Washington DC 20431, USA; email: eleborgne@imf.org
} 
"It is a general principle of human nature, that a man will be interested in whatever he possesses, in proportion to the firmness or precariousness of the tenure by which he holds it; will be less attached to what he holds by a momentary or uncertain title, than to what he enjoys by a durable or certain title; and, of course, will be willing to risk more for the sake of the one, than for the sake of the other."

Hamilton (1788), Federalist Paper 71: The Duration in Office of the Executive

"Many governments wisely try to depoliticize monetary policy by, for example, putting it in the hands of unelected technocrats with long terms of office and insulation from the hurly-burly of politics" (emphasis added)

Blinder (1998), pp. 56-57.

\section{Introduction}

One of the central questions of the political economy of the government is what decisions should be made by politicians that are subject to frequent elections and what decisions should be delegated to bureaucrats in independent agencies that, by design, have a longer time horizon than politicians? Students of political economy observe large variations in institutional arrangements of different countries at different times. In most countries, for example, fiscal policy decisions are made by politicians. On the other hand, complex tasks, such as interpreting the constitution, are often carried out by public officials with longer employment contracts. ${ }^{2}$ The judges at the U.S. Supreme Court, for example, are appointed for life, and are independent of/unaccountable to the (elected) executive. ${ }^{2}$ Another striking example of a complex task that is left to the bureaucrats is monetary policy. In contrast to fiscal policy, monetary policy is often delegated to an independent institution that is governed by career public officials whose terms of office are longer than the average political cycle. ${ }^{4}$ The accountability of these officials to elected representatives varies across countries.

In this paper, we tackle the following questions: why do politicians willingly relinquish a sizable part of their remit and power, and delegate it to bureaucrats in independent institutions? And what form might this delegation take (i.e., delegation of instruments, of goals)? We address

\footnotetext{
${ }^{2}$ Besley and Coate (2001) contrast direct election with political appointment of regulators in a model where electing regulators produces more pro-consumer regulators. (Assuming that regulation is not a salient issue for voters at large, political parties then have an incentive to appoint a regulator who shares the preferences of the regulated industry's stakeholders rather than voters' since for the former the preferences of the regulator is a salient issue.)

${ }^{2}$ Maskin and Tirole (2004) investigate the optimal allocation of power between accountable and nonaccountable branches of the government (e.g., a politician and a judge, respectively). One key trade-off associated with accountability is that, although it can screen and discipline office-holders, it also induces them to pander to public opinion.

${ }^{4}$ Moreover, most independent central banks' policy decisions are taken by committees; committee members have staggered contracts, with only a small fraction of the membership being renewed in a given year, so that the committee as a whole does not face an end-of-term problem.
} 
these questions in the context of monetary policy, a domain where delegation (central bank independence) has gained momentum across the world, especially during the 1990s. An application to monetary policy is also worthwhile from a theoretical perspective since the foundation of existing theories of central bank independence - the existence of an inflation bias - has been subject to criticisms. We attempt to answer these two questions, first in a general framework, and then in the monetary policy context.

We propose a theory of delegation based on optimal contract theory that has roots in corporate finance. We model two trade-offs of delegation in a representative democracy. The cost of delegation is that the electorate is unable to get rid of incompetent officeholders. ${ }^{3}$ Thus, if the ability of job candidates cannot be ascertained perfectly prior to hiring (a realistic feature of any hiring decision), and hired candidates are given strong job security and a long-term contract (e.g., a supreme court justice or a central banker), society may be stuck with an incompetent bureaucrat for a long time. The benefit of delegation, however, is that the officeholder is provided with a long-term employment contract, enabling him to have a long-term horizon which may improve his performance. In particular we show that if there is (symmetric ${ }^{4}$ ) uncertainty about the ability of the officeholder, a longer employment contract gives the long-term appointee an incentive to invest more effort into his decision making, thereby increasing the quality of his decisions. We label this beneficial effect the learning-by-doing effect. ${ }^{5}$

After illustrating the basic principles of our political agency theory, we use it to establish a theory of central bank independence (CBI). To do this we extend a stochastic general equilibrium model. The resulting theory is different from other formalized theories of CBI - which all rely on the presence of an inflation bias in monetary policy as the reason for delegation. ${ }^{6}$ Our theory does not rely on the inflation bias, time inconsistency problem. The rationale for delegating monetary policy to an independent central banker is that he is given a long-term job contract; this, in turn, gives the central banker an incentive to put more effort into the policymaking process than an elected politician would. This extra effort translates, in expectations, into better forecasts and fewer policy mistakes, which increases social welfare - and the politician's own utility - thereby

\footnotetext{
${ }^{3}$ This cost of delegation, however, is often mitigated in practice by the possible recourse, in extreme circumstances, to remove an officeholder for cause. The Federal Reserve has such a clause concerning its governors in its statutes, even though such a clause has never been used.

${ }^{4}$ Citizens and the officeholder himself have the same information set, which is that they only know about the distribution of ability in the economy.

${ }^{5}$ In an earlier version of the model (Eggertsson and Le Borgne (2003)), instead of a learning-by-doing effect, we emphasized an experimentation effect, whereby the officeholder supplies effort in the short-term to discover more rapidly his true ability. This channel is theoretically more subtle (and mathematically much more complicated) but produces very similar qualitative effects.

${ }^{6}$ In a classic article, Rogoff (1985) — building on Kydland-Prescott and Barro-Gordon's inflation bias problemshows that appointing a central banker who is more conservative than society improves the credibility-flexibility trade-off. Persson and Tabellini (1993) and Walsh (1995) suggest that optimally chosen state-contingent wage contracts for the central banker can eliminate the inflation bias and achieve the second-best equilibrium. Finally, Svensson (1997) and Lockwood (1997) show that inflation targets given by society/government to the central banker can be a means to achieve these optimal contracts. (see Drazen (2000), and Persson and Tabellini (2000) for a textbook exposition of these models and the literature.)
} 
making delegation incentive compatible.

Interestingly, our approach is consistent with Alan Blinder's (1998), former Vice-Chairman of the Federal Reserve, description of the rationale for delegating monetary policy to an independent agency, namely that "monetary policy, by its very nature, requires a long time horizon."

Since our theory does not rely on any dynamic inconsistency problem, it also answers some of the criticisms of existing CBI theories (e.g., McCallum (1995), Blinder (1998), Vickers (1998), and Posen $(1993,1995))$. First, is the argument that, in practice, central bankers do not attempt to target a level of output exceeding the natural rate - so that central banks do not suffer from an inflation bias. If we believe in this argument, then the economic literature does not offer us a formalized rationale for establishing independent central banks. A second criticism applies to the recent contracting approach (Persson and Tabellini (1993), Walsh (1995), Svensson (1997)) to solving the inflation bias (assuming it is a significant problem) stemming from a dynamic inconsistency problem. As argued by McCallum (1995) and others, this approach "merely relocates" the problem, it does not solve it. Another type of critique (Posen, 1993, 1995) is that the observed relationship between inflation and central bank independence observed in the data does not reflect - as existing theories claim - a causal relationship, but is simply due to an omitted variable problem: namely citizens' preferences towards inflation, which leads them to develop institutions that support these preferences. In our theory, central bank independence endogenously arises (or not) based on citizens' preferences; our model therefore answers Posen's endogeneity criticism.

A key critique on the literature on central bank is independence is that, since dynamic inconsistency problems are, arguably, even more acute in the domain of fiscal policy (taxation on capital being a prime example) rather than monetary policy, why is it that fiscal policy is not delegated to an independent agency? In our theory the delegation of a policy task depends on three factors: (1) the complexity of the task (2) on the level of rent that the officeholder derives from managing it, and (3) the ability of the politician to find a suitable candidate for the position (which depend on how ability is distributed across the relevant pool of candidates). It is quite plausible, and is indeed the conventional wisdom, that the effects of monetary policy (often described as more art than science!) are considerably more complex than most other public policy choices. It is also quite likely that politicians derive more rent (either in the form of prestige, or in more direct, monetary forms: pork, corruption, etc.) from fiscal policy than from monetary policy. Finally while it may be simple for a politician to select a candidate to appoint for monetary policy (whose job is to target a well defined criterion and whose qualification to do that job - such as an economic $\mathrm{PhD}$ - are easily verified) it may be more difficult to gauge whether a candidate is well suitable to conduct fiscal policy. Fiscal policy depends in large part on hard-to-define and constantly shifting preferences of the public and it may be hard to ascertain ex ante if a job candidate is capable of meeting (or willing to meet!) the constantly changing wants and needs of the public. Any of these factors can explain why many democracies put monetary policy in the hands of independent institutions but keep fiscal policy in the hands of politicians.

Our approach also enables us to address, from a different perspective, an important issue of the delegation process: what form does delegation takes when it occurs? That is, should the central 
bank have instrument and goal independence (using Debelle and Fischer's (1994) terminology), where the former applies to a central bank that has the power to determine its own goal(s), and the latter refers to a central bank that has the power to use its policy tools freely and to make its policy decisions without political interference-regardless of whether its goals are determined by politicians or not). The Bank of England is an example of an instrument independent but goal-dependent central bank, while the U.S. Federal Reserve, although being also instrument independent, ${ }^{7}$ is closer to being goal independent. ${ }^{11}$ A consensus exists in the literature that instrument independence is desirable, however, there is less agreement on goal independence. On the one hand, Rogoff's (1985) conservative central banker has both goal and instrument independence (he is given control over monetary policy and can freely maximize his own utility ${ }^{12}$ ). On the other hand, the contracting approach (e.g., Walsh, 1995) (generally ${ }^{8}$ ) advocates instrument independence but goal dependence: the central banker is the agent of a principal (government, parliament) to which he is accountable. The contracting approach however has been criticized on various grounds. ${ }^{14}$ We show that, in our model, instrument independence can be an optimal strategy for a politician and, when this arises, this is always a welfare-increasing strategy for society. We also show that, when the conditions for independence are satisfied, the politician prefers to grant the central bank goal independence, even though this strategy produces lower social welfare than a regime where the central bank is goal dependent; In a democratic society, goal dependence of the central bank ensures that the current majority of the voting population cannot suppress the preferences and goals of a future majority.

We derive five key empirical predictions of our theory - the first two are macroeconomic predictions while the last three are related to contractual, social, and political variables; these latter set of predictions is new to the literature. The first prediction is that CBI results, on average, in lower inflation, both in terms of level and variability. This arises in our model because, when monetary policy is delegated, the central banker supplies more effort in forecasting shocks, thereby

\footnotetext{
${ }^{7}$ Barring an act of Congress, a Federal Reserve decision on monetary policy cannot be reversed by political authorities. Congress has never used this procedure since the creation of the Fed in 1913.

${ }^{11}$ The Fed's mandate is cast in very broad terms and covers conflicting tasks (to purse both "maximum employment" and "stable prices") leaving its governing body ample latitude in interpreting and assigning relative weights among those objectives.

${ }^{12}$ As pointed by Fischer (1995), "the government tries to choose the right central banker, but - as in the case of Supreme Court justices - the behavior of a central banker may be different after appointment than before." (p. 202.)

${ }^{8}$ Muscatelli (1998) shows that, when there is uncertainty about central bank preferences (a realistic feature), then "the central bank may be made more accountable by allowing it to set its own targets, i.e., by making it goal-independent" (p. 529 )

${ }^{14}$ In particular, aside from McCallum's (1995) critique described above, as pointed by Walsh (1995) himself, the effectiveness and implementability of his contractual approach is questionable (the use of state-contingent wage contracts). In Svensson's (1997) inflation-targeting approach, the equilibrium inflation is always higher than the inflation target set by the politician to the central banker; the central banker is therefore in breach of its contractual goal but the politician is, in fact, very happy with such an outcome. Another weakness of the contractual approach is the reliance on explicit pecuniary contracts, which are well known to be low powered in the public sector (Wilson, 1989).
} 
getting more accurate forecasts and less policy errors. Second, CBI results in lower output variability. This, again, arises because of the better forecasts of the central banker, which result in fewer destabilizing monetary policy errors. Third, the longer the tenure of central bank governors, the lower are the first two moments of inflation and the volatility of the output gap. Fourth, CBI should only be observed in countries where the central bank governing body has a longer time horizon in office than the elected politicians that would otherwise be in charge of monetary policy. (Dictators are therefore not expected to appoint independent central bankers!) Finally, our fifth prediction is that the more corrupt a country, the less independent its central bank. The macroeconomic predictions are broadly consistent with the large empirical studies on CBI and macroeconomic outcomes, although the "stylized facts" in this literature are not uncontroversial. We present preliminary evidence that our last three predictions are also consistent with the data.

Our contracting model builds on the seminal career concerns model of Holmström (1982/1999) ${ }^{9}$ and on an extension of this model to a political economy environment (Le Borgne and Lockwood's (2003) where the manager in Holmström's model is replaced by an elected official with a fixed rent from office instead of an endogenous wage). Our game structure and production function, however, differ from the latter model in several respects. The career concerns model seems particularly suited to an electoral environment for two reasons. First, financial incentives to motivate elected officials are extremely limited compared to the various schemes available in the private sector (e.g., bonus, stock options, etc.); the compensation package of elected officials (or central bankers) is limited to a fixed salary and some perks, both of which are unrelated to their performance on the job: pecuniary incentives are low powered for elected officials (and civil servants). Second, counterbalancing these low-powered pecuniary incentives is the threat of dismissal at election time. As Barro (1973) and Ferejohn (1986) have first shown, through this mechanism, elections help citizens to "control" politicians.

In a closely related recent contribution, Alesina and Tabellini (2003) address, in a similar contracting environment as our Section 2 (i.e., a career concerns model), the issue of task allocation among politicians and bureaucrats. A key difference ${ }^{10}$ with our model is that they address the issue from a positive perspective (i.e., an exogenous "constitutional stage" exists whereby tasks are allocated to either a politician or a bureaucrat), while we take a normative approach and investigate whether, starting from a (realistic) position where tasks are entrusted to a politician, a politician would ever endogenously delegate a task to a bureaucrat? Interestingly, Alesina and Tabellini motivate their model by citing CBI as a prominent example of task delegation. Contrarily to their paper, we formalize this specific issue. By embedding a political agency model into a monetary policy model, this enables us to investigate the specific issues related to a politician's

\footnotetext{
${ }^{9}$ Holmström shows that a manager of unknown ability can be induced to supply effort by relying, not on explicit incentives, but on the manager's concerns about his future career; i.e., implicit incentives motivate the manager. Holmström's model does not contain elections.

${ }^{10}$ Other differences between our models is that Alesina and Tabellini's features multiple tasks which enables them to address a wider set of issues, but, contrarily to ours, their model is static; Also, Alesina and Tabellini need to assume that politicians and bureaucrats have different motivations whereas, in our model, politicians and bureaucrats share the same preferences (but face different incentives due to their different job contracts).
} 
decision to delegate monetary policy or not, and to derive specific macroeconomic results. The conclusions reached by Alesina and Tabellini confirm, and in some respect complement, ours.

The outline of the paper is as follows. Section 2 develops our basic political agency framework. Section 4 applies the model of Section 2.1 to a monetary policy context. It illustrates the rationale for central bank independence; differentiates and analyzes two concepts of independence (instrument and goal independence); and then draws some empirical predictions of the theory. Finally, Section 5 concludes and draws some policy implications.

\section{The Framework}

The economy is populated by a set $N$ of citizens with $\# N=n>3$ and evolves over two time periods, $t=1,2$. There is a political office that can be occupied by only one citizen, the "officeholder". In this representative democracy, the officeholder is entrusted with (and held accountable for) the economy's public good. (We can think of this public good as being monetary policy). The game begins with a politician as the officeholder. The politician can however decide whether to produce the public good himself or to delegate it to an appointed agent, which we call a "technocrat" (e.g., a central banker).

\subsection{Political Agency Setup}

We present a simple setup where citizens' utilities are a function of a public good. The production of this good requires an officeholder whose ability and effort enter the production function of the public good.

\subsubsection{Citizens' Preferences}

A citizen $j$ has a total payoff

$$
v_{t}^{j}=v_{t}^{c}\left(e_{t}^{o}, \theta^{o}\right)+Z(j)\left[R-c\left(e_{t}^{o}\right)\right]
$$

where $v_{t}^{c}($.$) is a payoff common to all citizens (superscript " c$ ") at time $t$; this payoff depends on the production of a public good which itself is an increasing function of the effort $\left(e_{t}^{o}\right)$ and ability $\left(\theta^{\circ}\right)$ of the officeholder (superscript " $O$ "). $Z($.$) is a binary variable which is equal to one if citizen$ $j$ is the officeholder, and zero otherwise, i.e.,

$$
Z(j)= \begin{cases}1 & \text { if } j=o \\ 0 & \text { if } j \neq o\end{cases}
$$

$R$ is an "ego rent" from being in office and managing the public good (as in Rogoff and Sibert, 1988), deriving from the prestige associated with managing public affairs, and $c($.$) is a function$ representing the cost of effort the officeholder expands in managing the public good. We assume that $c($.$) is strictly increasing and convex, and c(0)=0, c l(0)<1 .{ }^{17}$ To simplify the notation, we omit the index " $o$ " to $e_{t}$ and $\theta$ since only the officeholder's effort and ability matter to citizens.

\footnotetext{
${ }^{17}$ The last condition $c^{\prime}(0)<1$ ensures that myopic effort is positive.
} 


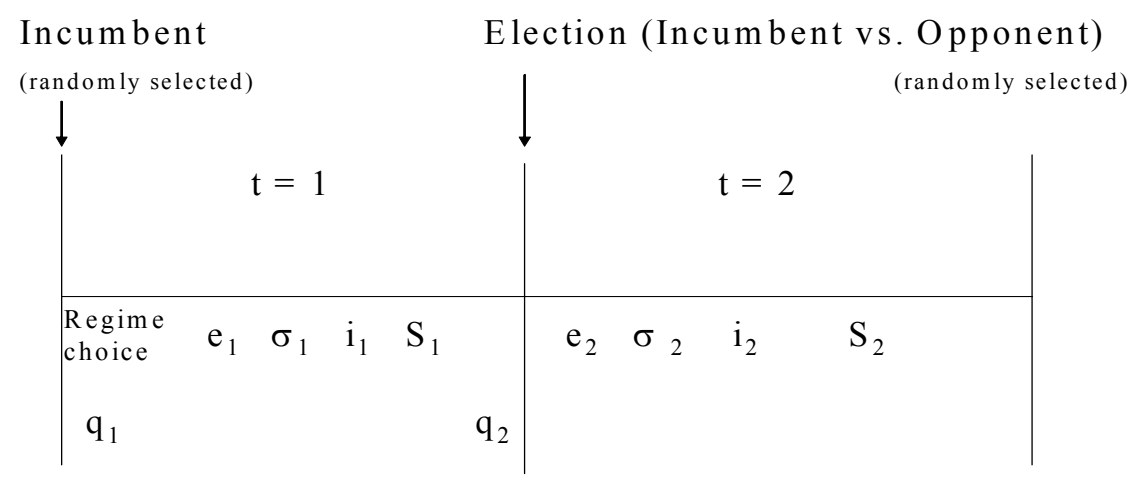

Figure 1: Time line

\subsubsection{Time Line}

The time line (depicted in Figure 1) is the following. First, at the beginning of game (immediately after being "elected"), the politician has to decide whether to produce the public good himself or to delegate it. ${ }^{18}$ Then, at the beginning of each period $t=1,2$, whoever is the officeholder has to decide how much effort to exert in order to receive a signal $\sigma_{t}$ (make a forecast) about a shock $S_{t}$ that will occur later in the period. Before observing the shock he needs to make a policy decision $i_{t}$ (e.g., setting nominal interest rates in the monetary policy context). High competence of the officeholder and high effort both make the officeholder more likely to increase social welfare, since he is better able to forecast the consequence of his policy decision.

\subsubsection{Institutions}

The politician (randomly selected from the set of citizens), once "elected" at the beginning of period $t=1$ decides to have the public good being produced under one of two possible institutions/regimes:

Delegation

At the beginning of period $t=1$, the politician $j$ appoints an agent (a technocrat) to be officeholder and produce the public good. Since all citizens are ex ante identical, this agent is randomly selected by the politician from the set of citizens, and is (contractually) in office for both periods. When the politician delegates the production of the public good (i.e., forecasts and the

\footnotetext{
${ }^{18} \mathrm{As}$ is standard in the contract theory literature, it is assumed that whatever the type of contract the politician (principal) writes with the central banker (agent), it is enforceable in court by both parties so that unilateral breach of the contract is not possible (or, alternatively, entails a prohibitive cost).
} 
associated policy decisions) his utility then becomes the same as that of a (representative) citizen (he is not in charge of producing the public good, so $j \neq o$ in (1)) except that he receives a small political rent from office $R^{D}$. This captures the idea that the elected office confers some prestige to the politician, the fact that voters, who in equilibrium understand the motives for delegation, view favorably a politician who delegates a task (say monetary policy), as citizens know that this is welfare increasing for them (this is shown later in the paper), or the fact that the politician is the principal of the technocrat, a position that confers some "ego rent".

\section{Political control}

At the beginning of period $t=1$, the elected politician decides to produce the public good himself. The politician is in office during period $t=1$ but faces an election at the beginning of period 2. At this stage, an opponent is randomly selected from the set of remaining citizens. The citizens then vote on the opponent versus the incumbent, and the winner is the officeholder in period $t=2$.

Our modeling of democracy abstracts from the entry decisions of candidates while allowing the electorate to "fire" bad officeholders. As shown in Le Borgne and Lockwood (2003), given the assumption of symmetric incomplete information, this simplification has no effect on the equilibrium outcome of the game. ${ }^{22}$

In both cases, for consistency, we impose the individual rationality condition that the officeholder prefers to be in office than not.

\subsubsection{Forecasting Technology}

To make our point in the simplest setup possible, we assume that two signals and two shocks can occur, i.e., $\sigma_{t} \in\left\{\sigma^{H}, \sigma^{L}\right\}, S_{t} \in\left\{S^{H}, S^{L}\right\}$, and $p=\operatorname{Pr}\left(S=S^{H}\right), 1-p=\operatorname{Pr}\left(S=S^{L}\right)$. The combination of the officeholder's forecast and the realization of the shock produce a state $s$. Four possible states can therefore arise in a given period depending on whether the shock (labeled as $H$ or $L)$ has been rightly $(R)$ or wrongly $(W)$ predicted: i.e., $s=S \sigma \in\{H R, H W, L R, L W\}$. The probability that the officeholder receives signal $\sigma$ conditional on the shock being $S$, his effort level $e$, and expected ability $\theta$ is $f_{s}\left(e_{t}, \theta\right)$, i.e.,

$$
f_{S \sigma}\left(e_{t}\right) \equiv \operatorname{Pr}\left(\sigma_{t}=\sigma^{j} \mid S_{t}=S^{i}, e_{t}, \theta,\right) ; \quad i, j \in\{H, L\}
$$

where, if $i=j$ then $f_{S \sigma}\left(e_{t}\right)=f_{i R}\left(e_{t}\right)$, and if $i \neq j$ then $f_{S \sigma}\left(e_{t}\right)=f_{i W}\left(e_{t}\right)$. In (3) above, $\theta$ is a random draw from a distribution that can take two values "good" or "bad", i.e.: $\theta_{G}>\theta_{B} \geq 0$ with probabilities $q_{1}$ and $1-q_{1}$, respectively. We refer to $a \in\{G, B\}$ as the (ability) types of the citizens. We assume that citizens do not know $\theta=\left(\theta_{1}, \ldots, \theta_{n}\right)$ but all know the joint distribution of $\theta$ (i.e., there is symmetric incomplete information, as in Holmström (1982/1999)). Note that $0 \leq f_{S \sigma}\left(e_{t}\right) \leq 1$.

Following Holmström (1999), we assume that the quality of the output being produced by the officeholder (i.e., the forecast) is an increasing function of both ability $(\theta)$ and effort $(e)$, i.e., in

\footnotetext{
${ }^{22}$ The assumption of exogenous candidate entry would not be innocuous should we have assumed asymmetric rather that symmetric incomplete information (see Le Borgne and Lockwood, 2002)
} 
the first period

$$
f_{S R}\left(e_{1}\right)=\operatorname{Pr}\left(S=S^{i}\right)+\theta+e_{1} ; \quad f_{S W}\left(e_{1}\right)=\operatorname{Pr}\left(S=S^{i}\right)-\theta-e_{1} ; \quad i \in\{H, L\}
$$

where $\operatorname{Pr}\left(S=S^{i}\right) \leq f_{S \sigma}\left(e_{t} \mid \theta\right)<1$. In the second period, two production functions are possible depending on who the officeholder is. When the first-period officeholder is in office in period two, because of an assumed learning-by-doing effect, we have

$f_{S R}\left(e_{2}\right)=\operatorname{Pr}\left(S=S^{i}\right)+\left(\theta+\beta e_{1}\right)+e_{2} ; \quad f_{S W}\left(e_{2}\right)=\operatorname{Pr}\left(S=S^{i}\right)-\left(\theta+\beta e_{1}\right)-e_{2} ; \quad i \in\{H, L\}$

where the coefficient $\beta>0$. We interpret this coefficient as corresponding to the complexity of the task at hand since it implies that effort put in the first-period translates into better learning for period two forecasting. For a complex task one would expect job experience and learning on the job to be extremely important while less relevant for simple or manual task. Adding the term $\beta e_{1}$ in the second period production function is a simple and transparent way of introducing a learning-by-doing effect, i.e., experience in office increases the ability of the officeholder. Thus, effort in the first-period is akin to a (sunk cost) investment; if the first-period officeholder is also in office in the second period, his effort invested in learning (say about the functioning of an economy, the structure of the central bank, etc.) means his accumulated (task specific) knowledge gives him an incumbency advantage compared to a new officeholder.

In the case where there is a new officeholder in period 2, the initial incumbent's individual specific learning is lost, so that

$$
f_{S R}\left(e_{2}\right)=\operatorname{Pr}\left(S=S^{i}\right)+\theta+e_{2} ; \quad f_{S W}\left(e_{2}\right)=\operatorname{Pr}\left(S=S^{i}\right)-\theta-e_{2} ; \quad i \in\{H, L\}
$$

We believe that learning-by-doing is of paramount importance in professional and highly specialized jobs such as central banking. However, as shown in an earlier (and more complex) version of this paper (Eggertsson and Le Borgne, 2003), other dynamic effects arising from the interaction of effort and ability can be analyzed instead of a learning-by-doing effect. In that earlier version of the paper we focused on an experimentation motive; i.e., the desire of an officeholder to learn as quickly as possible his true ability type so as equate his true marginal cost of effort to his marginal benefit. (technically, this arises when effort and ability enter multiplicatively in the production function; e.g., $\left.f_{S R}\left(e_{t}\right)=\operatorname{Pr}\left(S=S^{i}\right)+\theta e_{t}\right)$. We showed that the type and length of the job contract provided to the officeholder affect his level of effort, to the point where it can be welfare enhancing for a politician to delegate, at the beginning of period one, the production of the public good to a long-term appointee.

\section{Baseline Illustration}

While the officeholder needs to exert effort to receive a good signal, we assume that he does not need to exert any effort to make the policy decision. A central banker, for example, does not need to put in much effort to set interest rates; rather, he supplies effort to understand the consequences 
of his policy choice. We first consider the most simple case in which the officeholder has only a binary decision to make, e.g. whether or not to change interest rates (by a fixed amount that is exogenously given). We denote his policy decisions by $i^{H}$ and $i^{L}$. Since this decision is binary it will only depend on the officeholder's expectation about whether the future state is $H$ or $L$. It follows then that in case he receives the signal $\sigma^{H}$ he chooses $i^{H}$ and if he observes $\sigma^{L}$ he chooses $i^{L}$. A representative citizen's utility is $V^{H R}$ if the officeholder receives a high signal (and thus chooses $i^{H}$ ) and the state of nature turns out to be $H$ (i.e., the officeholder made the right forecast) and $V^{H W}$ if he receives the high signal but the real state of nature turns about to be $L$ (he made the wrong forecast). Similarly $V^{L R}$ is the loss of a citizen when the officeholder receives the low signal and is right and $V^{L W}$ if he is wrong. ${ }^{11}$

We can now specify $v_{t}^{c}\left(e_{t}, \theta\right)$, the utility of a representative citizen, as:

$$
v_{t}^{c}=-\sum_{a} \sum_{s} q^{a} f_{s}\left(e, \theta_{a}\right) V^{s}
$$

where $V^{s} \geq 0$ is the $\left(\right.$ constant $\left.^{20}\right)$ loss function associated with state $s \in\{H R, H W, L R, L W\}$, and $0 \leq V^{H R}=V^{L R}<V^{H W}=V^{L W}$.

To simplify the presentation in this section of the paper we simplify the model by assuming symmetric uncertainty so that $p=q_{1}=\frac{1}{2}$, and that $\theta_{B}=0$. We also assume that there are no losses associated with making a correct forecast so that $V^{H R}=V^{L R}=0$ and normalize the loss of making a wrong policy decision (i.e., making the wrong forecast) to $V^{H W}=V^{L W}=1$. The cost of effort function is $c(e)=\alpha e^{2} / 2$, with $\alpha>0$. We discuss the results of the general model whenever it is necessary. General expressions are available upon request. All the key results described with these parameter values carry to the general case.

\subsection{Equilibrium}

In order to decide whether to produce the public good himself or to delegate it, the politician has to compare his utility under both regimes. This, in turn, is a function of the equilibrium level of effort and ability expected under these regimes.

\subsubsection{Myopic Choice of Effort}

We solve the officeholder's decision problem with the usual dynamic programming approach. In the last period $(t=2)$ we have a static game; we call the resulting effort choice as "myopic." The maximization problem of the officeholder (politician or technocrat) is to ${ }^{12} \max _{e} U=E^{\theta} E^{S}\left[v^{o}\right]$, i.e., to

$$
\max _{e} U=\left\{R-\frac{1}{2} \alpha e_{2}^{2}\right\}-\left\{\frac{1}{2}-E \theta-e_{2}\right\}
$$

\footnotetext{
${ }^{11}$ We could of course also define notation for the case when the policy maker chooses $i^{L}$ even if he receives a signal $\sigma^{H}$. But since this will never happen in equilibrium, that notation is redundant.

${ }^{20}$ In Section 4, we endogenize this loss function.

${ }^{12}$ For ease of exposition, the (obvious) time subscript is omitted.
} 
The first bracket is the net rent from office (net of the cost of effort). The second bracket is the probability of the officeholder choosing the wrong policy decision. This probability is decreasing in effort and expected ability of the officeholder, denoted $E \theta$. If the officeholder was not in office in the previous period then $E \theta=\frac{1}{2} \theta_{G}$ (given our assumed parameter values). If the officeholder was in office in the previous period then $E \theta=\frac{1}{2} \theta_{G}+\beta e_{1}$ because of the learning by doing effect explained above. Recall that we assume, for simplicity, that $V^{H R}=V^{L R}=0$ so that the probability of making the right decisions does not appear in this utility function (this simplification has no effect on our results). Also recall that we normalized $V^{H W}=V^{L W}=1$ so that there is nothing that scales the probability in the utility function. The first order condition of this maximization problem is $c^{\prime}\left(e_{1}\right)-1=0$ so that equilibrium effort, denoted $e^{* 13}$, is:

$$
e^{*}=\alpha^{-1}>0
$$

Note that the effort choice does not depend on $E \theta$, thus it is independent of the officeholder's ability and his tenure. The same holds true in the more general model, but in that case the equilibrium level of effort is a function of the spread in utility arising from wrongly forecasting the shock and rightly forecasting it. The larger this spread the higher the incentive to increase effort and receive a more accurate forecast.

\subsubsection{Dynamic Effort Level Under Delegation}

In case the politician endogenously delegates the forecasting and policy decisions, the first-period problem of the tenured technocrat (superscript " $T$ ") is to $\max _{e_{1}} U_{1}^{T}=E_{1}^{\theta} E_{1}^{S}\left[v_{1}^{o}\right]+E_{1}^{\theta} E_{1}^{S}\left[v_{2}^{o}\left(q_{2}\left(e_{1}\right)\right)\right]$, which, with the simplifying parameter values assumed, reduces to

$$
\max _{e_{1}} U_{1}^{T}=\left\{2 R-\frac{1}{2} \alpha e_{1}^{2}-\frac{1}{2} \alpha e_{2}^{2}\right\}-\left\{\frac{1}{2}-\frac{1}{2} \theta_{G}-e_{1}\right\}-\left\{\frac{1}{2}-\frac{1}{2} \theta_{G}-\beta e_{1}-e_{2}\right\}
$$

The first bracket captures, again, the net rents from office of the technocrat. The second (third) bracket is the probability of taking the wrong policy decision in period one (two). Note that the probability of making a mistake in period 2 is also a function of effort in period 1 because of the learning-by-doing effect.

This leads to first order condition $c^{\prime}\left(e_{1}^{T}\right)-(1+\beta)=0$ so that the first-period equilibrium level of effort of a technocrat is

$$
e_{1}^{T}=\frac{1+\beta}{\alpha}>0
$$

Inspection of the first order condition reveals that the first-period effort level is composed of two terms; the first (1) is the first-period (myopic) gain from a small increase in effort, while the second $(\beta)$ represents the marginal benefit from changing $e_{1}$ from its myopic level $e^{*}$; we call this term the learning-by-doing effect. In the general case, the first-order equation shows the

\footnotetext{
${ }^{13}$ Because of the simple additive production function assumed, $e^{*}$ is independent of $q$. In an earlier version of the paper, Eggertsson and Le Borgne (2003), $e^{*}$ was a function of $q$. This complication does not affect the qualitative results of the paper.
} 
equilibrium level of effort as a function of the spread in first- and second-period utility arising from wrongly forecasting the shock and rightly forecasting it, and also as a function of the complexity of tasks $(\beta)$. This is because effort in period one has a long-lasting effect on the officeholder's forecasting ability.

It is clear that from this that effort is greater in period 1 than the myopic effort level, i.e.,

$$
e_{1}^{T}=\frac{1+\beta}{\alpha}>e^{*}=\frac{1}{\alpha}>0
$$

\subsubsection{Dynamic Effort Level without Delegation}

This case is more complex, as we have a game of incomplete information. We characterize the perfect Bayesian equilibria (PBE) of this game. Suppose first that the opponent $k \in N$ to the incumbent $l \in N$, is elected for the second period of the game (i.e., he defeats the first-period incumbent). His choice of effort is $e_{k, 2}=e^{*}$, because he has no additional information about his own competence. So, the expected utility to any citizen $l \neq k$ from electing the opponent is $v_{2}^{c}\left(q_{1}\right)$.

Now, at the time the electorate votes, every citizen has had the chance to observe $S_{1}$ and $\sigma_{1}$, the first-period shock and the incumbent's signal, respectively. Voters then update, using Bayes rule, their belief that the incumbent is a good type. When forming the posterior $q_{2}$ by using Bayes rule, citizens rationally deduce that in the first period, the incumbent has taken equilibrium action $e_{1}^{P}$ (the superscript $P$ stand for politician). Let their posterior probabilities that the incumbent is competent be $q_{2}^{c}\left(S_{1}, \sigma_{1}\right)$. Note that we use the $c$ superscript to distinguish citizens' posterior from the first-period officeholder's own (state-contingent) posterior. ${ }^{14}$ However, note that in equilibrium, $q_{2}^{c}\left(S_{1}, \sigma_{1}\right)=q_{2}\left(S_{1}, \sigma_{1}\right)$.

Then, the second-period expected utility that citizens can expect from the incumbent is $v_{2}^{c}\left(q_{2}^{c}\left(S_{1}, \sigma_{1}\right)\right)$. So, given the tie-breaking rule, all the citizens (apart from the incumbent and the opponent) will vote for the incumbent if and only if $v_{2}^{c}\left(q_{2}\left(S_{1}, \sigma_{1}\right)\right) \geq v_{2}^{c}\left(q_{1}\right) ;^{31}$ after some direct algebraic manipulations, this reduces to

$$
e_{1}+\left(q_{2}^{S \sigma}-\frac{1}{2}\right) \theta_{G} \geq 0
$$

From the above inequality we can see that, because of the learning-by-doing effect, the firstperiod officeholder has an incumbency advantage (equal to $e_{1}$ ). The second term is positive in case of a correct forecast (the posterior $q_{2}^{R}$ is greater than $q_{1}=0.5$ ) and negative otherwise. In order to focus on election versus appointment of officeholder, we assume that $e_{1}<\left(\frac{1}{2}-q_{2}^{W}\right) \theta_{G}$.

\footnotetext{
${ }^{14}$ The technocrat's posterior beliefs, $q_{2}\left(e_{1}, S_{1}, \sigma_{1}\right)=\operatorname{Pr}\left(\theta=\theta_{G} \mid e_{1}, S_{1}, \sigma_{1}\right)$ is obtained from Bayes rule. Since there are four possible states $s \in\{H R, H W, L R, L W\}$, four posteriors need to be formed. From Bayes rule, i.e., $q_{2}^{s}=\frac{q_{1}}{q_{1}+\left(1-q_{1}\right) L R_{s}}$, where $L R_{s}$ is the likelihood ratio for state $s$, i.e., $L R_{s}=\operatorname{Pr}\left(\sigma_{1} \mid e_{1}, \theta_{B}, S_{1}\right) / \operatorname{Pr}\left(\sigma_{1} \mid e_{1}, \theta_{G}, S_{1}\right)$. Note that $0<L R_{R}<1<L R_{W}$, and therefore $0 \leq q_{2}^{W}<q_{1}<q_{2}^{R} \leq 1$, where the subscripts $R$, $W$ stand for the states where the forecast were, respectively, right and wrong $(R \in\{H R, L R\}$, and $W \in\{H W, L W\})$.

${ }^{31}$ As there are more than three citizens by assumption, this voting strategy determines the outcome of the election, i.e., how the incumbent and the opponent vote is irrelevant.
} 
This assumption simply implies that, if the incumbent correctly forecast the shock $S_{1}$, then he is re-elected (if not, voters elect the opponent instead - since $q_{2}^{W}<\frac{1}{2}$ ).

We now need to ensure that it is individually rational for both the incumbent and the opponent to stand for election, given voters' cutoff rule. The net gain to winning the election for the incumbent is

$$
v_{2}^{o}\left(q_{2}\left(S_{1}, \sigma_{1}\right)\right)-v^{c}\left(q_{1}\right)=2\left[e_{1}+\left(q_{2}^{S \sigma}-\frac{1}{2}\right) \theta_{G}\right]+R-c\left(e^{*}\right)
$$

The individual rationality condition requires that this gain be positive. For this to be the case, we impose the weak assumption that $R \geq c\left(e^{*}\right)$, i.e., that the net rent from office is nonnegative.

We can now write the second-period equilibrium continuation payoff of the incumbent conditional on $S_{1}, \sigma_{1}, e_{1}$, i.e.,

$$
w\left(S_{1}, \sigma_{1}, e_{1}\right)= \begin{cases}v_{2}^{o}\left(q_{2}\right), & \text { if }\left(S_{1}, \sigma_{1}\right)=\{H R, L R\} \\ v_{2}^{c}\left(q_{1}\right), & \text { if }\left(S_{1}, \sigma_{1}\right)=\{H W, L W\}\end{cases}
$$

Given the continuation payoff (14), the choice of first-period policies and effort of the incumbent politician solves $\max _{e_{1}} U_{1}^{D}=E_{1}^{\theta} E_{1}^{S}\left[v_{1}^{o}\right]+E_{1}^{\theta} E_{1}^{S}\left[w\left(e_{1}, q_{2}\right)\right]$, where

$$
\begin{aligned}
U_{1}^{P}= & \left\{R-\frac{1}{2} \alpha e_{1}^{2}\right\}+\left\{\frac{1}{2}+\frac{1}{2} \theta_{G}+e_{1}\right\}\left(R-\alpha e_{2}^{2}\right)-\left\{\frac{1}{2}-\frac{1}{2} \theta_{G}-e_{1}\right\} \\
& -\left\{\frac{1}{2}+\frac{1}{2} \theta_{G}+e_{1}\right\}\left\{\frac{1}{2}-\frac{1}{2} \theta_{G}-\beta e_{1}-e_{2}\right\}-\left\{\frac{1}{2}-\frac{1}{2} \theta_{G}-e_{1}\right\}\left\{\frac{1}{2}-\frac{1}{2} \theta_{G}-e^{*}\right\}
\end{aligned}
$$

The difference between this expression and utility of the technocrat $\left(U_{1}^{T}\right)$ is that the politician is uncertain whether or not he will stay in office in period 2. This is the reason why the net rent of office in period 2, i.e., $\left(R-\alpha e_{2}^{2}\right)$, is multiplied by $\left\{\frac{1}{2}+\frac{1}{2} \theta_{G}+e_{1}\right\}$ which is the probability of the officeholder of being right in period 1. If he is wrong, he loses the election in the beginning of period 2. The third curly bracket corresponds, as in the delegation case, to the probability of making a wrong decision in period 1 . The first term of the second line corresponds to the loss of utility associated with making a wrong forecast in period 2 and this term is weighted by the probability of the politician still being in office. Finally the last term is the utility of the politician in period 2 if he gets the policy wrong in period 1, weighted by the probability of that happening (note that in this case he will receive the same utility as the average citizen and the outcome does not depend on his effort in period 1 or 2 ).

The first order condition with respect to effort is:

$$
c^{\prime}\left(e_{1}\right)=\alpha e_{1}=\left(R-\frac{1}{2 \alpha}\right)+1+\beta\left(\frac{1}{2}+\frac{1}{2} \theta_{G}+2 e_{1}\right)
$$

so that the $e_{1}$ that solves $(16)$, denoted $e_{1}^{P}$, is

$$
e_{1}^{P}=\frac{\left\{1+\beta\left(\frac{1}{2}+\frac{1}{2} \theta_{G}\right)\right\} V^{W}+\left\{R-\frac{1}{2 \alpha}\right\}}{\alpha-2 \beta}>0
$$

We show in the appendix that the denominator of this expression has to be positive. There are two effects that have an effect on the politician's effort, the learning-by-doing effect and the 
career concerns effect. As already discussed, the former is related to the complexity of the task and of expected first-period ability of the officeholder, while the latter is an increasing function of the net rent from office. Under the delegation regime this effect was not present since the net rent is irrelevant given that the officeholder is in office in period two with probability one. The career concerns effect (extending Holmström's terminology to the political/administration context) captures the incentive the first-period incumbent has to increase effort above its myopic level so as to raise the probability of staying in office and receiving the net (private) rent from office on top of the utility that each (representative) citizen obtains. The career concerns effect could also be coined a tournament effect (Lazear and Rosen (1981); Green and Stokey (1983)), since it induces extra effort through the reward of a prize (the private rent) which is only available to the winner of the election.

\subsection{Endogenous Delegation of Political Power}

\subsubsection{Welfare and the Existence of the Trade-offs Between Regimes}

We can now analyze whether a newly elected politician has an incentive to endogenously delegate the policy decision. Recall that, by assumption, if a politician delegates the policy decision but still remains in office (e.g., as the principal of the technocrat), he gets a rent $R^{D}>0$ that is strictly less than the net rent from office that the technocrat obtains. Let us call the politician's utility when he delegates (and gets rent $R^{D}$ but supplies no effort) $U^{D}$ and recall that we denote his utility $U^{P}$ if he does not delegate. Thus the politician delegates iff

$$
U^{D}>U^{P}
$$

where, after substituting the equilibrium effort values into the above equation, we get

$$
U^{D}=2 R^{D}-1+\theta_{G}+\frac{(1+\beta)^{2}+1}{\alpha}
$$

which is only a function of the structural parameters $R^{D}, \theta_{G}, \beta$ and $\alpha$. Note that this utility is an increasing function of $\theta_{G}$ with a slope of 1 . The utility of the politician if he does not delegate can also be written in terms of the structural parameters by substituting (8) and (17) into (15). We can express $U^{P}$ in terms of a quadratic function of $\theta_{G}$ so that

$$
U^{P}=\gamma_{1}+\gamma_{2} \theta_{G}+\gamma_{3} \theta_{G}^{2}
$$

where

$$
\gamma_{3}=\left(\frac{1}{4} \frac{\beta^{2}}{\alpha-2 \beta}+\frac{1}{4} \frac{\beta^{3}}{(\alpha-2 \beta)^{2}}-\frac{1}{8} \alpha \frac{\beta^{2}}{(\alpha-2 \beta)^{2}}\right)>0
$$

We show in the appendix that $\gamma_{3}$ must be positive for all permissible parameters in the model. Therefore, utility is increasing in $\theta_{G}$ in the positive quadrant of $\left(U^{D}, \theta_{G}\right)$ space.

The generic form of $U^{P}$ and $U^{D}$ as a function of $\theta_{G}$ (or, in the general case where $\theta_{B} \neq 0$ : $\left.\theta_{G}-\theta_{B}\right)$ is shown in Figure 2 below. The curve when the politician chooses not to delegate is denoted "politician" while the curve when he chooses to delegate is denoted "technocrat". 


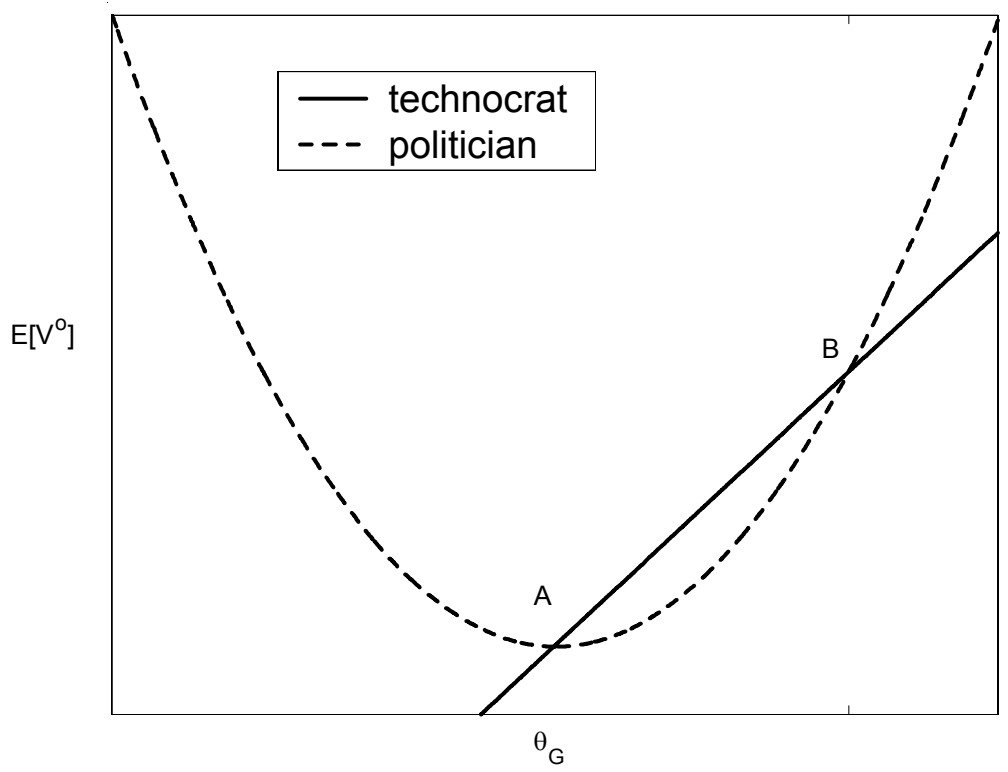

Figure 2: Possible cutoff for welfare

As can be seen, there are, in general, two possible intersections for these curves. However, only one of them is an admissible equilibrium of our model, namely point $B$. To see this suppose that point $\mathrm{A}$ is an equilibrium. Note that the slope of the $U^{P}$ curve is smaller than that of $U^{D}$. Consider now the utility under Delegation. Using (19) we have

$$
\frac{\partial U^{D}}{\partial \theta_{G}}=1
$$

and, using the envelope theorem, we can calculate the slope of $U^{P}$ by taking a partial derivative of (15) to obtain:

$$
\frac{\partial U^{P}}{\partial \theta_{G}}=1+\frac{1}{2}\left(R-c\left(e_{2}\right)\right)+\frac{1}{2} \theta_{G} \beta e_{1}>\frac{\partial U^{D}}{\partial \theta_{G}}
$$

but we know that this cannot be the case in point $A$ (because the slope of $U^{P}$ line in Figure 2 is smaller than the technocrat line). So this cannot be an equilibrium for the parameter values we assume (i.e., positive rents and positive effort).

The discussion above indicates that, for a given set of parameters, equilibrium will be on the right hand side of point $A$ in Figure 2. If the ability spread is in the range between $A$ and $B$ delegation dominates political control, while political control dominates delegation to the right hand side of $B$. To have an interesting theory of endogenous delegation we must show that an equilibrium exist on both sides of point $B$, depending on the parameters. If this can be established, we can discuss how the equilibrium depends on the parameter values and whether or not delegation occurs in equilibrium. Thus the question of most economic interest is whether there exists a trade-off between delegation and political control, i.e., are there configuration of the parameters on both sides of $B$ that satisfy all the restrictions of the model? 
In addition to the welfare functions derived in equation (19) and (20) a candidate solution has to satisfy the conditions that i) the implied probabilities of every event are between 0 and 1 , ii) effort is positive, and iii) the individual rationality constraints of the politician and technocrat are satisfied. The proof of the existence of this policy trade-off is trivial. We only need to establish a numerical example that shows that for one set of parameters delegation dominates and in another it does not. This example is given below. With existence of solution established we can discuss how the welfare trade-off depends on the different parameters of the model. That discussion does not require any of parameter values in example 1, only that the assumed parameters satisfy the necessary conditions for an equilibrium discussed above.

Example 1. Suppose that the coefficients of the model are $\left(\theta_{G}, R, R^{D}, \alpha, \beta\right)=(0.2,0.2,0.15,100,1)$. This implies that $\left(e_{1}^{T}, e_{1}^{P}, e^{*}, U^{D}, U^{P}\right)=(0.02,0.018,0.01,-0.45,-0.46)$, i.e., $U^{D}>U^{P}$, the necessary conditions are satisfied, and that delegation dominates. If we assume instead that $\theta_{G}=0.4$ (and the same values for the other parameters) then $\left(e_{1}^{T}, e_{1}^{P}, e^{*}, U^{D}, U^{P}\right)=(0.02,0.0193,0.01,-0.25,-0.2402)$, i.e. $U^{D}<U^{P}$, the necessary conditions are satisfied, and delegation is dominated so that the politician retains control.

\subsubsection{The Welfare Trade-off}

The last section established that endogenous delegation can occur and that whether or not it happens depends on the parameters of the model. In other words the nature of the policy task has an effect on whether or not delegation takes place. It can be individually rational for a self-interested politician to delegate policy decisions to an independent but accountable officeholder. In this case the officeholder becomes the agent of the elected politician, who himself is the representative of citizens at large. It is also clear that the individual rationality constraint of an appointed officeholder is satisfied since he also gets a strictly positive private rent from office so that he is better off than the rest of the citizenry, including his principal, the politician. We learned that utility of the officeholder is increasing in $\theta_{G}$ whether or not he delegates power but it increases more if he retains power, i.e., the slope of $U^{P}$ is greater than $U^{D}$.

The relationship between the utility of the politician with and without delegation is shown in Figure 3 below. This figure corresponds to the right hand side of point $A$ in Figure 2. For small values of the ability parameter, delegation to a technocrat dominates. As $\theta_{G}$ increases (or, more generally, the spread between $\theta_{G}$ and $\theta_{B}$ ) the utility of the politician of retaining power increases until the two lines cross so that the politician will not appoint a technocrat. The intuition is straightforward and captures - albeit in a crude fashion - the main trade-off between delegation and democratically accountable power: if the politician appoints an independent technocrat he cannot be fired! If there is great uncertainty about the ability or "type" of the technocrat, the politician will be increasingly reluctant to give away power that extends beyond his election term because society can be stuck with an incompetent technocrat that cannot be removed.

This cost may not be trivial and is crucial for many tasks that are delegated in practice. Supreme Court Justices in the US, for example, are appointed for life and the contract for each 


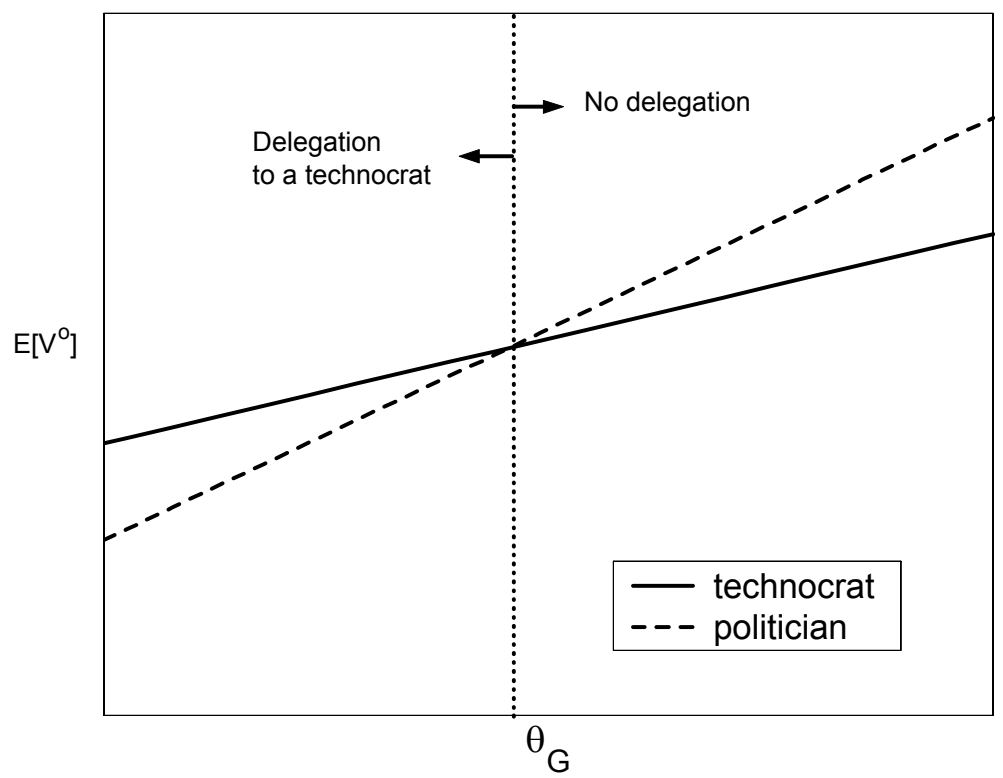

Figure 3: Basic tradeoff of delegation

governor of the Board of Governors at the Federal Reserve is 14 years. ${ }^{15}$ The slope of the two curves, therefore, indicates that the politician will be more willing to delegate power to technocrats if he can easily identify whether or not the candidates are qualified to handle it, since this implies a lower spread between $\theta_{G}$ and $\theta_{B}$. In the case of a Governor of the Federal Reserve, for example, one may argue that it is fairly easy to identify the necessary qualification of a candidate (e.g. experience in banking or academia, a Ph.D. etc.). The nature of the task at the Federal Reserve is also fairly uncontroversial and well agreed upon (i.e., keeping inflation low with some weight on business cycle fluctuations). Similarly before appointing someone to the Supreme Court the politician can observe the track record of the technocrat (i.e., the judge) and the objective of the judge are fairly well agreed upon (interpreting the constitution). Arguably the ability of technocrats to perform some other tasks may be subject to greater uncertainty. Some public offices (fiscal policy?) for example depend on interpreting the wishes and needs of the electorate which may shift over time. In this case technical qualification may not be sufficient for determining whether a candidate is suitable for appointment or not, which is an argument for the politician to maintain power in his own hands.

There are other parameters, however, that can lead to endogenous delegation, namely the complexity of the task and rents from office.

\footnotetext{
${ }^{15}$ Although the cairman is appointed for a shorter period.
} 


\subsubsection{Comparative Statics}

Having established the existence of a trade-off between delegating power and retaining it and showed how it depends on the expected ability of the officeholder we now turn to analyzing the effect of the complexity of tasks and rents.

Task Complexity $(\beta)$ We are interested in knowing the effect at the margin (i.e., around the cutoff point of the two curves in Figure 3) of increasing the complexity of the forecasting task. To do this, we take the partial derivative of $U^{D}$, i.e.,

$$
\frac{\partial U^{D}}{\partial \beta}=e_{1}=2 \frac{1+\beta}{\alpha}
$$

We can use the envelope theorem to calculate the derivative of $U^{P}$ with respect to $\beta$, i.e.,

$$
\frac{\partial U^{P}}{\partial \beta}=e_{1}\left(\frac{1}{2}+\frac{1}{2} \theta_{G}+e_{1}\right)
$$

We then evaluate these derivatives in the case where the two curves intersect (i.e., $e_{1}=(1+\beta) / \alpha$ ). Then we have

$$
\frac{\partial U^{P}}{\partial \beta}=\frac{1+\beta}{\alpha}\left(\frac{1}{2}+\frac{1}{2} \theta_{G}+e_{1}\right)<\frac{\partial U^{D}}{\partial \beta}
$$

and the inequality follows because we know that $\left(\frac{1}{2}+\frac{1}{2} \theta_{G}+e_{1}\right)<1$.

So, the more complex a task is, the more desirable it is to delegate power as shown in Figure 4 below. First, observe that increasing $\beta$ shifts both curves up so that it increases welfare in both regimes. The reason is that in both cases the officeholder will inherit his effort in period 1 (in the case of the politician this only increases welfare if he is reelected) and the higher $\beta$ the more useful this will be for policy. The result above illustrates, however, that utility with delegation (the solid curve) increases by more than utility if the politician retains power. The key reason for this is that the technocrat has a higher stake in being in office (because he cannot be fired) so that his effort in period 1 is more sensitive to the learning parameter. In contrast, the envelope theorem implies that if the politician conducts the policy task then $\partial e_{1}^{P} / \partial \beta=0$ (when this derivative is evaluated at the optimal $e_{1}^{P}$ ). Since the utility of the politician (and society in general) is increasing in the effort of the technocrat in period one an increase in effort by the technocrat raises utility.

The conclusion, then, is that the more complex the task, the more important it is to give it to a technocrat with a long-term contract because the long-term benefit of being in office gives him the incentive to invest in learning (supplying effort). This in effect is reminiscent of Hamilton's claim in the Federalist Paper 71 about the "tenure of the executive" cited in the introduction. Hamilton states that "it is a general principle of human nature, that a man will be interested in whatever he possesses, in proportion to the firmness or precariousness of the tenure by which he holds it; will be less attached to what he holds by a momentary or uncertain title, than to what he enjoys by a durable or certain title; and, of course, will be willing to risk more for the sake of the one, than for the sake of the other." 


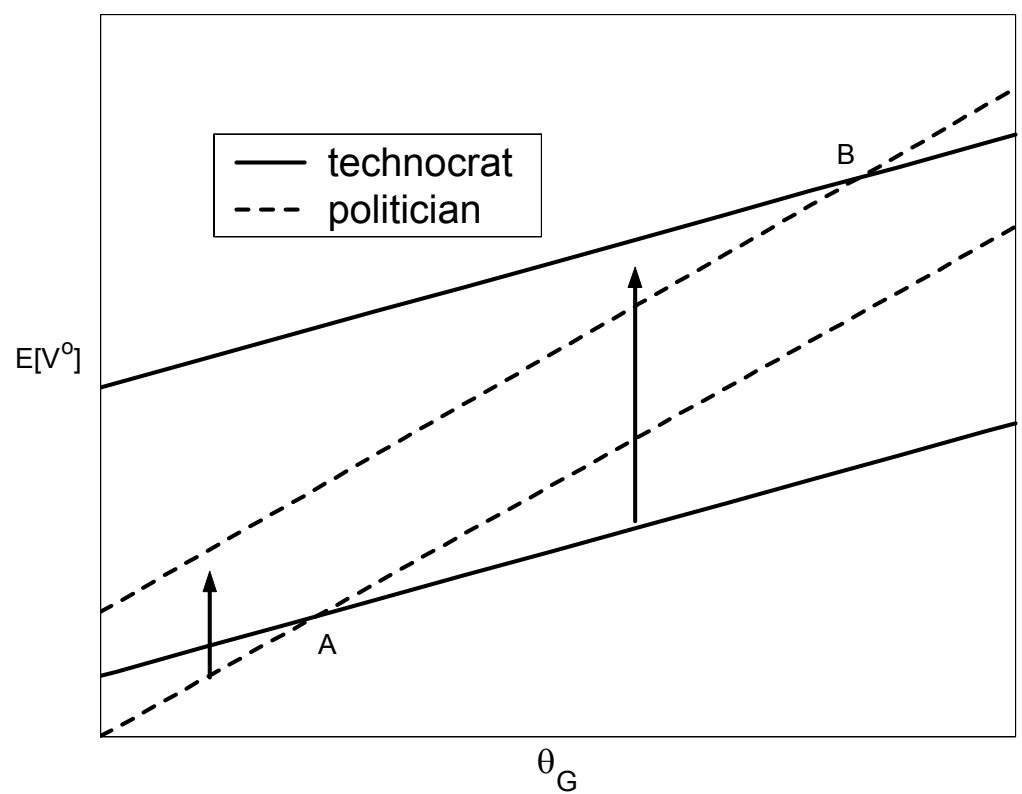

Figure 4: An increase in complexity of the task increases delegation.

Rents and Corruption Finally, we can also see that increasing $R^{P}$ will shift the democracy curve up. This makes delegation less likely. The intuition is immediate: delegation is a way for the politician to increase his utility (and that of a representative citizen) because it depends on the common good. However, delegation comes at the expense of forsaking the net private rent associated with managing the public good (this private benefit can range from an ego rent to outright corruption). To the extent that this private rent is large, the concern of the politician for the public good will be smaller so that he is less likely to delegate.

So, to summarize:

Proposition 1. (Endogenous delegation of political power). In the equilibrium of the model the set of variables $\left(e_{1}^{T}, e_{1}^{P}, e^{*}, U^{D}, U^{P}\right)$ depends on the set of variables $\left(\theta_{G}, R, R^{D}, \alpha, \beta\right)$. Delegation occurs if $U^{D}>U^{P}$. Both delegation and non-delegation equilibrium exist and which arises depends on the value of the parameters $\left(\theta_{G}, R, R^{D}, \alpha, \beta\right)$. For the policy task the following holds at the margin:

i) An increase in the complexity of the task, $\beta$, increases the incentive to delegate,

ii) An increase in the rent from office, $R$, reduces the incentive to delegate,

iii) An increase in the uncertainty of the ability of the officeholder, $\theta_{G}$, reduces the incentive of delegate.

The proof of existence of both equilibria follows from Example 1 and the second part of the proposition follows from the discussion in the sections above. 


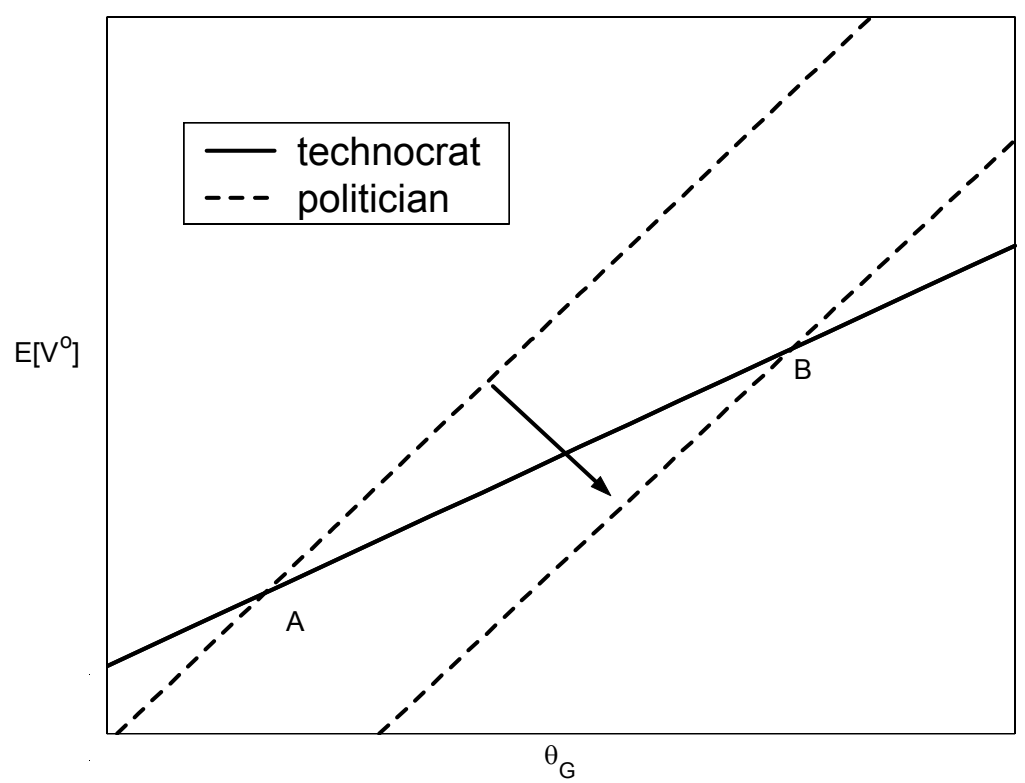

Figure 5: A decrease in corruption increases delagation.

\subsection{Social welfare and delegation}

Proposition 1 establishes a theory of delegation. It shows that the decision to delegate depends on the properties of the policy task and how it affects political rents. The question we now turn to is whether or not delegation is optimal for society as a whole (if it occurs) rather than only from the perspective of the politician. The question is under what circumstances $U_{c}^{D}>U_{c}^{P}$ where $D$ denotes delegation, $P$ that the politician retains power and $c$ denotes that utility refers to the representative citizen. Observe that the politician's utility is the sum of his private rent from office and the citizens utility $U_{c}^{D}$ or $U_{c}^{P}$. Assuming that the policy makers delegates it is then straight forward to show that this is socially optimal if

$$
2 R^{D}<2 R-c\left(e_{1}^{P}\right)-c\left(e_{2}^{P}\right)
$$

This condition implies that as long as the private "rent" the politician gets by delegating power is smaller than the net rent he extracts without giving up power, delegation will always be socially optimal. We consider this to be a sensible condition to impose. The case when delegation occurs because the politician can extract higher private rents by doing it is theoretically uninteresting because in that case one could always engineer delegation by making $R^{D}$ arbitrarily high. It is seems implausible that a politician would receive higher private rents from the public office by giving it to someone else! Indeed imposing condition (22) makes our theory more interesting - and plausible - because it implies delegation can be optimal for the politician even if it reduces his net private rents.

So, to summarize:

Proposition 2. Assume condition (22) holds. When delegation occurs, it is socially optimal. 
Even if delegation is always socially optimal under condition (22) the politician may choose not to delegate even if it is socially optimal to do so. In other words we may have the condition $U_{c}^{D}>U_{c}^{P}$ but $U^{D}<U^{P}$. This can arise if the politician receives high private rents from conducting the policy himself and the increase in general welfare by delegation is not enough to compensate the politician for his loss in private rents. In this case it would be optimal for the society to force the politician to delegate by constitutional rules.

\section{Central Bank Independence}

As stressed by Milton Friedman, monetary policy operates with "long and variable lags." Monetary policy is therefore conducted on the basis of forecasts about the state of the economy. Indeed, central banks such as the U.S. Federal Reserve, the European Central Bank, or the Bank of England expend a large amount of resources into their forecasting divisions and these forecast are described to the public as the key underlying reason for monetary policy decisions. In this section, we capture this aspect of the conduct of monetary policy by integrating our microfounded political agency framework with a simple macro model.

In the next section (Section 4.1), we show that there can be a rationale for delegating monetary policy to an independent central banker, where independence refers to instrument independence (agents have homogenous preferences so that there are no goal differences). In Section 4.2, we allow for heterogeneity of preferences among citizens so as to address the issue of goal accountability of the (instrument) independent central banker. Finally, Section 4.3 discusses our key theoretical predictions and confronts them (in a preliminary way) to the data.

\subsection{Instrument Independence}

The structure of the game is the same as in Section 2.1, except that now the policy decision for the officeholder (setting the nominal interest rate) affects the (endogenous) loss function. Again, at the beginning of the first period, the newly elected politician has to decide whether to perform monetary policy himself or to delegate it to an "independent (but accountable) central banker"; then, in each period, the official in charge of monetary policy supplies effort, receives a signal, and then chooses $i_{t}$, the nominal interest rate. After this the shock is observed and markets clear.

This timing structure accords with recent decisions to delegate monetary policy to independent central banks. In the United Kingdom, for instance, the first major policy decision of the newly elected Prime Minister Tony Blair in May 1997 was to grant independence to the Bank of England.

We first present a simple (and fairly standard) macro framework that illustrates that an independent central bank delivers lower inflation and output variability. We then show, in an extended version, that central bank independence also delivers lower average inflation. 


\subsubsection{Inflation and Output Variability}

Macroeconomic Setup We assume a simple stochastic general equilibrium macroeconomic model that is derived from microfoundations in Eggertsson (2003). For simplicity we follow much of the literature by using a linear approximation of the structural equations of the model and a quadratic approximation of the utility of the representative household.

The utility function of a (representative) citizen is given by:

$$
V_{1}^{c}=-E_{t} \sum_{t=1}^{2}\left[\frac{1}{2} \pi_{t}^{2}+\frac{1}{2} \lambda x_{t}^{2}\right]
$$

where $\pi_{t}$ is inflation and $x_{t}$ is the output gap, i.e., the deviation of output from the natural rate of output and $E$ is expectations formed at the beginning of the game. For simplicity we assume that agents discount the future at the same rate as the present. Under this assumption the loss function of citizens in period 1 can be expressed in terms of unconditional variances of inflation and the output gap

$$
V_{1}^{c}=-\frac{1}{2} \operatorname{var}(\pi)-\frac{1}{2} \operatorname{var}(x)
$$

We assume a simple expectation AS equation:

$$
\pi_{t}=k x_{t}+\pi_{t}^{e}+u_{t}, \quad t=1,2
$$

where $\pi_{t}^{e}$ denotes expectations of inflation that are formed before monetary policy is set in each period. Unexpected inflation causes an output boom because nominal wages are set before monetary policy is determined (see Eggertsson (2003) for details, and Eggertsson and Le Borgne (2003) for an analysis with a forward looking AS curve). $u_{t}$ is an i.i.d. shock $(E[u]=0)$.

We assume a simple IS equation that can be derived from the Euler equation of the representative household:

$$
x_{t}=-\varepsilon\left(i_{t}-r_{t}^{n}\right),, t=1,2
$$

where $i_{t}$ is the nominal interest rate and $r_{t}^{n}$ is the natural rate of interest. In the microfounded model, expectation about future inflation and future output gap appear on the right hand side of this equation. We suppress these terms for simplicity. Since inflation and output gap are zero in expectations in equilibrium, this abstraction has no effect on the derivations. In this model the natural rate of interest is only a function of exogenous shocks. It is the real rate of interest that would "clear the market", i.e., it is the real interest rate that is consistent with output being at the natural rate of output at all times. We assume that the central bank chooses $i_{t}$ in each period before the shock is realized so that the policy problem is exactly the same as discussed in Section 2 (but here the loss function $L_{t}$ is endogenous since it is a function of $\pi_{t}$ and $x_{t}$ ). We first consider a case where the only exogenous shock is $r_{t}^{n}$. In terms of our notation from Section $2.1 S_{t}=r_{t}^{n}$ and we assume that $r_{t}^{n}$ is equal to $r^{H}$ with probability $p$ and $r^{L}$ with probability $1-p$. For simplicity we limit ourselves to analyzing the equilibrium for two periods, as in previous 
sections. Accordingly we shall suppose that equations (25) and (26) refer to periods of fairly long duration. ${ }^{40}$

If the central bank could perfectly forecast the natural rate of interest, it would set $i_{t}=r_{t}^{n}$, resulting in zero inflation and output gap. This minimizes the bank's loss function. If the central bank cannot perfectly forecast the natural rate of output, this equilibrium may not be feasible. For example, if the central bank misses the target for the natural rate of interest so that $i_{t}<r_{t}^{n}$, there will be excessive inflation and output will be above its natural level. By contrast, if $i_{t}>r_{t}^{n}$ there will be deflation and output slump. Since the central bank sets the nominal interest rate before observing $r_{t}^{n}$, its problem is to predict the future value of $r_{t}^{n}$ in order to minimize its losses. Since monetary policy operates with long and variable lags we believe this feature of our framework captures, in a simple way, a realistic and basic problem facing modern central banks.

Equilibrium and Welfare We solve the officeholder's decision problem with the usual dynamic programming approach.

Myopic Policy and Effort Choices. In the last (second) period, the maximization problem of the officeholder is to

$$
\max _{\{e, i, \pi\}} E^{\theta} E^{S}\left[v^{o}\right]
$$

We analyze the Markov equilibria. The government treats expectations as constants and this reduces the problem to a one-period model.

From (25) and (26), we get

$$
\begin{aligned}
x & =-\varepsilon\left(i-r^{n}\right) \\
\pi & =-\varepsilon \kappa\left(i-r^{n}\right)+\pi^{e}+u \\
x & =-\varepsilon\left(i-r^{n}\right)
\end{aligned}
$$

where the government treats $\pi^{e}$ as some constant. After substitution of (28) and (30) into (27), the maximization problem of the officeholder becomes $\max _{\{e, i, \pi\}}-\sum_{a} \sum_{s} q^{a} f_{s}\left(e, \theta_{a}\right) V^{s}+R-c(e)$, where

$$
V^{S \sigma}=\frac{1}{2}\left(-\varepsilon \kappa\left(i^{\sigma}-r^{S}\right)+\pi^{e}+u\right)^{2}+\frac{1}{2} \lambda\left(-\varepsilon\left(i^{\sigma}-r^{S}\right)\right)^{2}
$$

and, as in Section 2.1, the subscript $S \sigma \in\{H R, L R, H W, L W\}$ refers to the combination of the shock $S \in\{H, L\}$ and the forecast $\sigma \in\{H, L\}$, i.e., whether $\sigma$ turns out to be a correct $(R)$ forecast about $S$ or not $(W)$.

After rearranging the first-order conditions (w.r.t. $e, i^{H}, i^{L}, \pi_{H R}, \pi_{H W}, \pi_{L R}, \pi_{L W}$ ), the

\footnotetext{
${ }^{40}$ It is possible, using the methods we illustrate, to generalize the model and allow for the game to evolve over several periods of shorter duration, without changing the basic insights.
} 
equilibrium values of $i^{H}, i^{L}, \pi_{H R}, \pi_{H W}, \pi_{L R}, \pi_{L W}$ are:

$$
\begin{aligned}
i^{H} & =\left(p+E_{2}[\theta] e\right) r^{H}+\left(1-p-E_{2}[\theta]-e\right) r^{L}+\frac{k}{\varepsilon\left(\lambda+k^{2}\right)} u \\
i^{L} & =\left(p-E_{2}[\theta] e\right) r^{H}+\left(1-p+E_{2}[\theta]+e\right) r^{L}+\frac{k}{\varepsilon\left(\lambda+k^{2}\right)} u \\
\pi_{H R} & =\varepsilon k\left(1-p-E_{2}[\theta]-e\right)\left(r^{H}-r^{L}\right)+\frac{\lambda}{\lambda+k^{2}} u \\
\pi_{H W} & =-\varepsilon k\left(p+E_{2}[\theta]+e\right)\left(r^{H}-r^{L}\right)+\frac{\lambda}{\lambda+k^{2}} u \\
\pi_{L R} & =-\varepsilon k\left(p-E_{2}[\theta]-e\right)\left(r^{H}-r^{L}\right)+\frac{\lambda}{\lambda+k^{2}} u \\
\pi_{L W} & =\varepsilon k\left(1-p+E_{2}[\theta]+e\right)\left(r^{H}-r^{L}\right)+\frac{\lambda}{\lambda+k^{2}} u \\
x_{s} & =k^{-1}\left(\pi_{s}-u\right) ; \quad s \in\{H R, L R, H W, L W\}
\end{aligned}
$$

where $E_{2}[\theta]=q \theta_{G}+(1-q) \theta_{B}+e_{1}$. Note here that we define the notation $E_{2} \theta$ as expected ability that includes the effort in the previous period. ${ }^{16}$ We can notice that, with an endogenous loss function, all the equilibrium values are now functions of the expected ability of the officeholder, i.e., $e=e^{*}(q)>0, i^{H}=i^{H *}(q), i^{L}=i^{L *}(q), \pi_{s}=\pi_{s}^{*}(q)$, and $x_{s}=x_{s}^{*}(q)$. To find the value for $e$ we again obtain condition (8); we can then substitute the endogenous values of $\pi_{s}$ and $x_{s}$ into the loss functions and obtain the solution for $e_{2}$, i.e.,

$$
e_{2}^{s_{1}}=\frac{\phi}{\alpha-\phi} E_{2}^{s_{1}} \theta, \quad s_{1} \in\{H R, L R, H W, L W\}
$$

where we assume that the cost function is $c(e)=\frac{1}{2} \alpha e^{2}$ and defined the following coefficient $\phi=$ $4\left(1+\frac{\lambda}{\kappa^{2}}\right) \varepsilon^{2} k^{2}\left(r^{H}-r^{L}\right)^{2}$. Note that we need $\alpha>\phi$ for an equilibrium with positive effort to exist. The effort choice depends on the realization of $s_{1}$ in period 1 since this has an effect on the expected ability of the office holder. Note that this implies that in the macroeconomic setup the effort choice can be higher under delegation in both period 1 and 2, whereas in our previous section the myopic effort choice was the same in period 2 across the two regimes.

The first-period allocation, as far as the macroeconomic variables is concerned (i.e., $i^{H}, i^{L}$, $\left.\pi_{s}, x_{s}\right)$, will be the same as those derived in (32)-(38) except that we replace $E_{2}[\theta]$ with $E_{1}[\theta]$ and in this case $e_{1}$ does not appear in the expression for $E_{1}[\theta]$. The derivation of the firstperiod equilibrium effort level follows directly from the analysis of Section 2.1 with the added analytical complication that the loss function is endogenous. Note that the derivations (32)-(38) imply that for given ability a higher level of effort reduces output and inflation variability. Since delegation implies higher effort this implies that if a politician delegates power then central bank independence leads to a reduction in both output and inflation variability. To summarize:

Proposition 3. (Lower Inflation and Output variability under Central Bank Independence) If citizens welfare is given by given by (23), condition (22) holds, and a politician

\footnotetext{
${ }^{16}$ However, as in Section 2, under Democracy, if the incumbent politician is not reelected, the $e_{1}$ term drops out.
} 
appoints an independent central banker then the variability of output and inflation declines compared to the regime where the politician sets monetary policy.

Our result resolves what has sometimes been considered as a limitation of the literature on central bank independence. Much of this literature implies (see, e.g., Rogoff, 1985) that society delegates policy to achieve lower inflation variability, but at the cost of inducing higher variability in output (for notable exceptions see, e.g., Alesina and Gatti (1995) and Schellekens (2002)). This prediction is not, as discussed in our empirical section, consistent with the data. In the data lower output and inflation variability usually go hand in hand (Alesina and Summers, 1993).

\subsubsection{Average Inflation}

The model derived in the previous section implies that average inflation is zero across regimes. This can be seen from equations (32)-(38). Here we show how the model can be extended to imply that central bank independence also implies lower average inflation. We now assume that society's loss function given by (23) is modified to:

$$
v_{t}^{c}=-V_{t}^{c}=-E_{t} \sum_{t=1}^{2} \sum_{s \in\{H R, L R, H W, L W\}} \beta^{t} \mu(s)\left[\frac{1}{2} \pi_{t}^{2}+\frac{1}{2} \lambda x_{t}^{2}\right]
$$

This is a generalization of the previous loss function since we now allow the loss function to depend on the state of the economy so that $\mu(s)$ can take four values, i.e., $s \in\{H R, L R, H W, L W\}$. This loss function allows for asymmetry across states of the economy. In particular, we consider the possibility that society attaches higher losses to a recession (i.e., a negative output gap and deflation) than to an expansion (i.e., a positive output gap and inflation). Thus we assume that $\mu^{H R}<\mu^{L R}$ and $\mu^{H W}<\mu^{L W}$ in equilibrium.

For a given level of effort, we can now solve for the optimal level of inflation, output and interest rate following the same steps as in the previous section. The only difference is that now $\pi^{e} \neq 0$. The resulting expressions for $\pi_{s}$ and $x_{s}$ are somewhat more complicated than before and are shown in and earlier version of this paper (see Eggertsson and Le Borgne (2003)) in a slightly more complicated model. What they illustrate is that a higher level of effort does not only reduce inflation and output variability but also the average level of inflation. The reason for this is simple. When the central bank weighs recessions and booms differently, average inflation is different from zero. Since the central bank puts a lower weight on an economic boom than on a recession, it sets the nominal interest rate as if it is giving a higher probability on the recessionary state relative to the solution derived in the previous section. This causes an average inflation bias that is unrelated to the standard inflation bias. ${ }^{44}$ What is immediately clear, however, is that a higher level of effort decreases average inflation since a higher level of effort improves the accuracy of the central bank's forecast. Since central bank independence, when it (endogenously) occurs,

\footnotetext{
${ }^{44}$ Using the word "bias" here may be somewhat misleading, since higher average inflation is optimal for this social loss function (as opposed to the standard inflation bias that is suboptimal and is due to inefficient lack of credibility).
} 
is associated with higher effort, central bank independence leads, not only to lower variability in output and inflation, but it also reduces the average level of inflation. To summarize:

Proposition 4. (Lower Average Inflation under Central Bank Independence). If the citizens welfare is given by given by (39), condition (22) holds, and a politician appoints an independent central banker then average inflation declines compared to the regime where the politician sets monetary policy.

\subsection{Goal and Instrument Independence}

The assumption of homogenous preferences precludes us from addressing an important issue related to CBI: namely whether to give the central bank instrument and goal independence as opposed to purely instrument independence (following Debelle and Fischer's (1994) terminology). In simpler terms: should the central bank be independent but accountable? To address this issue, we now relax the homogeneity of preferences assumption.

The structure of the game remains the same as in Section 4.1, except that we now assume that two possible types of citizens exist in the population (e.g., Democrat $D$, or Republican $R$ ), each with different preferences regarding the inflation-output trade-off: i.e., $\lambda_{D}>\lambda_{R}>0$ in (23). These preferences are common knowledge and constant over time for all but one individual, the median voter. The preferences of the median voter are varying over time according to a random walk process. Let us index by $m_{t}\left(-m_{t}\right)$ the group of citizen that shares the same preferences as that of the median voter at time $t=1,2$, i.e., the majority (the opposition); The (potential) shift in the preferences of the median voter occur at the same time as $q_{2}$ is formed (i.e., before the election).

\subsubsection{Myopic Equilibrium}

Two cases need to be analyzed: (1) the officeholder is a member of the majority ( $o=m \in\{D, R\})$; and (2) the officeholder has different preferences than the majority $(o=-m)$.

The Officeholder Belongs to the Majority $(o=m)$. In this case, the officeholder's maximization problem is the same as in Section 4.1.1, namely: $\max _{\{e, i, \pi\}}-\sum_{a} \sum_{s} q^{a} f_{s}\left(e, \theta_{a}\right) V_{m}^{S \sigma}$ $+R-c(e)$. The associated equilibrium level of effort and of the macroeconomic variables is therefore the same as in Section 4.1.1. However, the expected utility of a citizen $c(c \in\{D, R\}$ and $c \in\{m,-m\})$ now depends on his preferences and that of the officeholder $o$ :

$$
v^{c}(o=m)=-\sum_{a} \sum_{s} q^{a} f_{s}\left(e^{*}(q), \theta_{a}\right) V_{c}^{s}\left(q, \lambda_{m}\right)
$$

so that $v^{c=m}(o=m)>v^{c=-m}(o=m)$.

The Officeholder Does Not Belong to the Majority $(o=-m) .{ }^{45}$ This is the interesting case since there is then a conflict of interest between the central banker and the majority of the

\footnotetext{
${ }^{45}$ This case only occurs in the Appointment regime.
} 
population. Two cases can potentially exist: (1) the central banker is both instrument and goal independent, and (2) the central banker is instrument independent but goal dependent.

The analysis of the first case is trivial from our previous analysis and is omitted. As for the second case, in our setup, a simple and feasible mechanism that holds the central banker goal dependent is to alter his private net rent from office from $R-c(e)$ to $R+\omega^{s}-c(e)$, where $\omega^{s}$ is a state contingent transfer ${ }^{46}$ determined by the second-period politician. ${ }^{47}$ An obvious choice is to have $\omega^{s}=\sum_{s} q^{a} f_{s}\left(e, \theta_{a}\right)\left[-\frac{1}{2} \lambda_{m}\left(x^{s}\right)^{2}+\frac{1}{2} \lambda_{-m}\left(x^{s}\right)^{2}\right]$, since, in that case, the officeholder's problem becomes: $\max _{\{e, i, \pi\}}-\sum_{a} \sum_{s} q^{a} f_{s}\left(e, \theta_{a}\right) V_{-m}^{s}+R+\omega^{s}-c(e)$, which is equivalent to $\max _{\{e, i, \pi\}}-\sum_{a} \sum_{s} q^{a} f_{s}\left(e, \theta_{a}\right) V_{m}^{s}+R-c(e)$ : i.e., the same problem as when the officeholder shares the majority's preferences. The equilibrium allocations are therefore the same as in Section 4.1.1 while the expected utilities of the various players differ depending on whether they belong to the majority or not:

$$
v^{c}(o=-m)=-\sum_{a} \sum_{s} q^{a} f_{s}\left(e^{*}\left(q, \lambda_{m}\right), \theta_{a}\right) V_{c}^{s}\left(q, \lambda_{m}\right)
$$

Therefore, $v^{o}(o=-m)>v^{c=m}(o=-m)>v^{c=-m}(o=-m)$.

\subsubsection{Dynamic Equilibrium}

Under Delegation. There is a probability $1-m$ that the median voter's preferences shift in the second period (which leads to the election of a politician with preferences that differ from those of the central banker). For illustration purposes, let us assume that the central banker is of type $c=D$, as is the first-period majority. Then, the central banker's first-period problem now becomes: $\max _{\left\{e_{1}, i_{1}, \pi_{1}\right\}} E_{1}^{\theta} E_{1}^{S}\left[v_{1}^{o}\right]+E_{1}^{m} E_{1}^{\theta} E_{1}^{S}\left[v_{2}^{o}\left(q_{2}\left(e_{1}\right)\right)\right]$, or

$$
\begin{aligned}
& \max _{e_{1}, i_{1}, \pi_{1}}-\sum_{a} \sum_{s_{1}} q_{1}^{a} f_{s_{1}}\left(e_{1}, \theta_{a}\right) V_{D}^{s_{1}}\left(q_{1}, \lambda_{D}\right)+R-c\left(e_{1}\right) \\
& -m \sum_{a} \sum_{s_{1}} q_{1}^{a} f_{s_{1}}\left(e_{1}, \theta_{a}\right) \sum_{s_{2}} f_{s_{2}}\left(e_{1}, e_{2}\left(q_{2}^{s_{1}}\left(e_{1}\right)\right), \theta_{a}\right)\left[\begin{array}{c}
V_{D}^{s_{2}}\left(q_{2}^{s_{1}}\left(e_{1}\right), \lambda_{D}\right) \\
-R+c\left(e_{2}\left(q_{2}^{s_{1}}\left(e_{1}\right)\right)\right)
\end{array}\right] \\
& -(1-m) \sum_{a} \sum_{s_{1}} q_{1}^{a} f_{s_{1}}\left(e_{1}, \theta_{a}\right) \sum_{s_{2}} f_{s_{2}}\left(e_{1}, e_{2}\left(q_{2}^{s_{1}}\left(e_{1}\right)\right), \theta_{a}\right)\left[\begin{array}{c}
V_{G}^{s_{2}}\left(q_{2}^{s_{1}}\left(e_{1}\right), \lambda_{G}\right) \\
-R+c\left(e_{2}\left(q_{2}^{s_{1}}\left(e_{1}\right)\right)\right)
\end{array}\right]
\end{aligned}
$$

where the second-period loss function $V_{G}^{s_{2}}\left(q, \lambda_{G}\right), G \in\{D, R\}$ depends on whether or not the central banker is goal dependent or not. If the majority shifts and the central banker of type $D$ is goal independent then $L_{G}^{s_{2}}\left(q, \lambda_{G}\right)=V_{D}^{s_{2}}\left(q, \lambda_{D}\right)$; however, if the central banker is goal dependent, then he is offered a contract $\omega^{s}$ that aligns his preferences to that of a citizen $c=R$ (the new majority) so that $V_{G}^{s_{2}}\left(q, \lambda_{G}\right)=V_{R}^{s_{2}}\left(q, \lambda_{R}\right)$.

\footnotetext{
${ }^{46}$ The state-contingent transfer is only one way through which a new majority can alter the behavior of the central banker. Arguably this is not a very realistic one but is made here only for the sake of simplicity of exposition. A more realistic approach would be to have the new majority / politician choose an inflation target for the central banker.

${ }^{47}$ The state-contingent benefit is financed by taxing the $n$ citizens in the economy an amount $\omega^{s} / n$. However, if $n$ is large, this tax becomes infinitesimal and can be neglected. This is our working assumption.
} 
Under Democracy. Compared to the game analyzed in Section 3.1.3 the politician can now be fired for two reasons: (1) a majority shift, and (2) incompetence, which we analyze in turn.

First, assuming again that the initial majority is $m=D$, if a majority shift arises (an event occurring with probability $1-m=1 / 2$ ), provided $A .1$. below holds, the incumbent $l \in D$ is replaced with an opponent $k \in R$ in the second period of the game. The expected utility to any citizen $R \neq k$ from electing the opponent is $v_{2}^{c=R}\left(q_{1}, o=R\right)$, while the expected utility of any citizen $D$ is $v_{2}^{c=D}\left(q_{1}, o=R\right)<v_{2}^{c=R}\left(q_{1}, o=R\right)$.

A.1. $v_{2}^{c, m_{2}}\left(q_{1}, o=m_{2}\right)>v_{2}^{c, m_{2}}\left(q_{2}, o=-m_{2}\right)$.

which just says that, if a new majority arises in period 2, its members always prefer to have an officeholder who shares their own preferences, regardless of the current incumbent's expected ability $q_{2}$ (For voters, an officeholder's "ideology" is a more salient issue than his "ability").

Second, provided the majority does not change from period 1 to 2 , if the politician $l \in D$ does not appear to be competent enough (specifically $q_{2}<q_{1}$ ), he is replaced by an opponent $k \in D$ in period 2 (as in Section 3.1.3). The expected utility to any citizen $D \neq k$ from electing the opponent is $v_{2}^{c=D}\left(q_{1}, o=D\right)$, while the expected utility of any citizen $R$ is $v_{2}^{c=R}\left(q_{1}, o=D\right)$ $<v_{2}^{c=D}\left(q_{1}, o=D\right)$.

The second-period equilibrium continuation payoff of the incumbent $l \in m_{1}$ conditional on $S_{1}, \sigma_{1}, e_{1}$ and $m_{2}$ is

$$
w\left(S_{1}, \sigma_{1}, m_{2}, e_{1}\right)= \begin{cases}v_{2}^{o}\left(q_{2}, o=m_{1}\right), & \text { if }\left(S_{1}, \sigma_{1}\right)=\{H R, L R\} \text { and } m_{2}=m_{1} \\ v_{2}^{c}\left(q_{1}, o=m_{2}\right), & \text { if } m_{2}=-m_{1}\end{cases}
$$

So, the expected second-period continuation payoff of the incumbent $l \in m_{1}$, conditional on first-period effort, $E[w()$.$] is equal to$

$$
\begin{gathered}
-m \sum_{a} q_{1}^{a}\left\{\begin{array}{c}
\left.\sum_{R} f_{R}\left(e_{1}, \theta_{a}\right) \sum_{s} f_{s}\left(e_{1}, e_{2}\left(q_{2}^{R}\left(e_{1}\right), o=m_{1}\right), \theta_{a}\right)\left[\begin{array}{c}
V_{m_{1}}^{s}-R \\
+c\left(e_{2}\left(q_{2}^{R}\left(e_{1}\right)\right)\right)
\end{array}\right]\right\} \\
+\sum_{W} f_{W}\left(e_{1}, \theta_{a}\right) \sum_{s} f_{s}\left(e_{1}, e_{2}\left(q_{1}, o=m_{1}\right), \theta_{a}\right) V_{m_{1}}^{s}
\end{array}\right\} \\
-(1-m) \sum_{a} q_{1}^{a} \sum_{s} f_{s}\left(e_{1}, \theta_{a}\right) \sum_{s} f_{s}\left(e_{2}\left(q_{1}, o=m_{2}\right), \theta_{a}\right) V_{m_{1}}^{s}\left(o=m_{2}\right)
\end{gathered}
$$

Given the continuation payoff (44), the choice of first-period policies and effort of the incumbent solves $\max _{e_{1}} E_{1}^{\theta} E_{1}^{S}\left[v_{1}^{o}\right]+E_{1}^{\theta} E_{1}^{m} E_{1}^{S}[w()$.$] .$

\subsubsection{Goal (In)Dependence and Welfare}

We can now analyze the pros and cons of goal independence, both from the politician's viewpoint and from society's.

From Section 4.1.1 we know that a politician only finds delegation of monetary policy worthwhile if the appointed central banker is given a long-term employment contract. With homogenous citizen preferences, the only relevant term of this contract is the length of employment. Now, with heterogenous preferences, it is easy to see that the politician who is writing the initial contract 
with the central banker has a private incentive ${ }^{48}$ to give the central banker a fixed goal/ fixed preferences, i.e., to have a central bank that is both instrument and goal independent. Arguably, such a regime could describe the U.S. Federal Reserve Board. The Board is clearly instrument independent and, given that its mandate is cast in very broad terms and covers conflicting tasks (to pursue both "maximum employment" and "stable prices"), its governing body is de facto the one that interprets and assigns relative weights among those objectives: i.e., it is goal independent.

Having established that goal independence is privately optimal for a politician (should he decide to delegate monetary policy), Proposition 5 analyzes whether it is also socially optimal:

Proposition 5. (Goal independence and social welfare). Compared to a regime where the tenured central banker is goal dependent, granting goal independence to a tenured central banker (1) lowers welfare of the future majority of the population to the benefit of the future minority (if there is a majority change from period 1 to 2); (2) always decreases expected social welfare if the gains and losses are symmetric.

Proof. Assuming the first-period majority is $m_{1}=D$, expected total utility $W^{c}$ of the two types of citizens is the following: (1) with a goal independent central bank, $W^{c=D}=E\left[v_{1}^{c=D}(o=D)\right]+$ $m E\left[v_{2}^{c=D}(o=D)\right]+(1-m) E\left[v_{2}^{c=D}(o=D)\right]$ and $W^{c=R}=E\left[v_{1}^{c=R}(o=D)\right]+m E\left[v_{2}^{c=R}(o=D)\right]$ $+(1-m) E\left[v_{2}^{c=R}(o=D)\right] ;(2)$ With a goal dependent central bank: $W^{c=D}=E\left[v_{1}^{c=D}(o=D)\right]$ $+m E\left[v_{2}^{c=D}(o=D)\right]+(1-m) E\left[v_{2}^{c=D}(o=R)\right]$ and $W^{c=R}=E\left[v_{1}^{c=R}(o=D)\right]+m E\left[v_{2}^{c=R}(o=D)\right]$ $+(1-m) E\left[v_{2}^{c=R}(o=R)\right]$. So, the only difference across the two regimes concerns the case where there is a majority change in the second period, an event occurring with probability $1-m$ : i.e., $E\left[v_{2}^{c=D}(o=D)\right]+E\left[v_{2}^{c=R}(o=D)\right]$ versus $E\left[v_{2}^{c=D}(o=R)\right]+E\left[v_{2}^{c=R}(o=R)\right]$, where, given A.3., $E\left[v_{2}^{c=D}(o=D)\right]>E\left[v_{2}^{c=D}(o=R)\right]$ and $E\left[v_{2}^{c=R}(o=D)\right]<E\left[v_{2}^{c=R}(o=R)\right]$. However, since in that case type- $D$ citizens now belong to the minority, with symmetric loss functions, goal independence increases the expected utility of the minority while decreases that of the majority compared to goal dependence.

The intuition for Proposition 5 is that when delegation occurs, the majority of the time appoints a central banker who shares its goals/preferences; if the next majority does not share these preferences, with a goal independent and tenured central banker, this majority's welfare is lower than if it could set the goal of the central banker. For the first-period politician and his supporting majority, a goal independent central bank has clear benefits: it constrain the policy decisions of the future majority.

Since goal independence is privately optimal for a politician but is not socially optimal, can society establish a mechanism (which constrains the private incentive of the partisan politician) and which is Pareto improving? One feature that is widespread in representative democracies is the following:

\footnotetext{
${ }^{48}$ It also seems that, ceteris paribus, the politician also has an incentive to marginally increase the length of the central banker's contract (although, given our simple two-period structure, we cannot directly address this (interesting) issue.
} 
A.2. A constitution exists and states that institutional regime changes (such as central bank independence) require a supermajority of the voting population.

which we take as given in our model. ${ }^{17}$ (Recall that the politician only has a simple majority of the population: he is elected by the median voter.) The politician however retains the initiative, i.e., he decides whether to propose delegation or not. Given A.2, institutional changes can only occur in our model if the two types of agents $(D$ and $R$ ) agree on the regime change.

Given the assumed constitution $(A .2)$, we can now answer the issue of the socially optimal type of independence that the central bank should be given.

Proposition 6. Given A1-A2 and that the conditions for delegation are satisfied, goal independence is not a politically feasible outcome, whereas goal dependence is both politically achievable and socially optimal.

Proof. From Proposition 5, it is clear that, in period 1, the opposition group (minority) will never vote for a regime where monetary policy is delegated to a goal independent central bank since, compared to the alternative (a goal dependent central bank), its expected utility is lower. But, given $A .2$, for a regime proposal to be accepted, it needs to gain the support of both types of agents $(D$ and $R)$; a goal independent central bank is therefore not a feasible political outcome. From Proposition 3 , we know that, when it is incentive compatible for the first-period politician to have instrument independence, the benefits arising from high effort (better forecasts) outweigh the cost of reduced expected ability of the officeholder. It is also trivial to see that both groups of citizens $(D$ and $R$ ) also get higher welfare from an instrument independent but goal dependent central banker than from a politician as the officeholder.

\subsection{Empirical Predictions and Evidence}

We now turn to the key predictions of our political agency theory of central bank independence:

- Independent central banks produce, on average, lower inflation, both in terms of level and variability. ${ }^{51}$

- Independent central banks generate, on average, lower output variability.

- The longer the tenure of central bank governors, the lower are the first two moments of inflation and the volatility of the output gap.

- Central bank independence should only occur in situations where the governing body of the central bank has a longer job contract than elected politicians. ${ }^{52}$

\footnotetext{
${ }^{17}$ This could easily be endogenized by adding a "constitutional" stage prior to the beginning of the game.

${ }^{51}$ This arises in our model because, when monetary policy is delegated, the central banker supplies more effort in forecasting shocks, thereby getting more accurate forecasts and less policy errors.

${ }^{52}$ Since otherwise, according to our theory, the politician, and society, would be better off with the politician setting monetary policy.
} 
- The more corrupt a country, the less independent its central bank should be (since politicians can extract more rent from office).

The first two predictions have been extensively tested in the literature since the existing inflation-bias-based models of CBI also give predictions regarding the correlation between central bank independence and macroeconomic variables such as inflation and output. From these empirical studies, a consensus has emerged on a few "stylized facts," even though some of these are still disputed and their robustness questioned (see, e.g., Drazen (2000), Persson and Tabellini (2000), and Berger et al. (2002) for a review of this literature). With this caveat in mind, we now confront our theoretical predictions with these "stylized facts."

The first prediction of our model, the link between inflation's first two moments and CBI, is supported by the data. In fact this relationship is a key stylized fact of the empirical literature (see, e.g., Grilli et al. (1991); and Alesina and Summers (1993) for early studies on the mean of inflation and Cukierman (1992) on its variance).

The second prediction has not been widely tested in the literature since existing inflationbias-based theories either predict higher or no output variability associated with CBI. ${ }^{18}$ The data strongly reject the former prediction and seem to accept the latter. Recent studies, however, (e.g., Lippi, 1998) find evidence of a statistically significant negative correlation between CBI and output variability. A result that we confirm below. We also present (preliminary) supportive evidence on our other predictions.

To test our predictions, we use a cross-country data set on central bank governors' turnover ("Turnover" variable) over the period 1980-89 first developed by Cukierman (1992) and later extended to 82 developing countries by de Haan and Kooi (2000). ${ }^{54}$ Our sample then covers 100 developed and developing countries. The frequency of elections data come from the Database on Political Institutions from the World Bank (Beck et al., 1999). ${ }^{55}$ From the turnover rate of governors and the frequency of elections, we construct a variable, "TurnElec," which is the difference between the former and the latter, i.e., how long is the tenure of a central bank governor compared to the electoral cycle. Our theory predicts that this variable is indicative of the degree of independence of a central bank. Indeed, while the turnover of the monetary policy decision maker is crucial in our model to explain a better (or worse) macroeconomic performance, the cross-country data on the turnover of central bank governor that we have are silent about where

\footnotetext{
${ }^{18}$ Exceptions include Alesina and Gatti (1995), Waller and Walsh (1996), and, more recently Schellekens (2002). Schellekens shows that Rogoff's prediction of a positive correlation between CBI and output volatility can be overturned by relaxing assumptions about uncertainty and preferences.

${ }^{54}$ As shown by Cukierman (1992) the turnover of central bank governors is a good indicator of actual central bank independence in developing countries (as opposed to a legal indicator of independence) since the enforcement of the law might be weak. In our model, the Turnover variable is not a proxy for actual independence but a key factor directly affecting the macroeconomic variables.

${ }^{55}$ This database reports all national elections that take place in a country, but since we are only interested in elections of the executive, we use DPI's classification of countries' political systems (presidential or parliamentary regime) and retain only the relevant elections (executive or legislative) to calculate the frequency of elections in a given country.
} 
the real monetary policy decision making rests (i.e., governor or treasury). The difference between the turnover of the governor and the frequency of the electoral cycle is, according to our theory, an indicator of this real authority and therefore a better indicator of central bank independence than the simple turnover of central bank governors. Another important variable, according to our theory, is a politician's rent from office. One aspect of this rent ${ }^{56}$ is the degree of "corruption within the political system" (Corrupt variable) as evaluated by the International Country Risk Guide (2002), a private international risk service company. Corrupt is a dummy variable taking a value of 0 (1) for countries without (with) important corruption problems. Finally, the macroeconomic variables (inflation - the change in the CPI: $\pi$-and unemployment as a percentage of the labor force $(U)$ - our measure of the output gap) come from the IMF's International Financial Statistics.

Table 1 reports some cross-country regressions (similar to those that exist in the empirical literature on central bank independence).

Table 1: OLS Regression Results

\begin{tabular}{llllllllllllll}
\hline & $D$ & $D$ & $D$ & $D$ & $S d \pi$ & $S d \pi$ & $S d \pi$ & $S d \pi$ & $S d U$ & $S d U$ & $S d U$ & $S d U$ & TurnElec \\
\hline Turnover & 0.10 & 0.10 & & & 11.9 & 11.3 & & & 3.2 & 2.1 & & & \\
& {$[.00]$} & {$[.00]$} & & & {$[.00]$} & {$[.00]$} & & & {$[.02]$} & {$[.11]$} & & & \\
TurnElec & & & 0.10 & 0.09 & & & 13.3 & 12.0 & & & 2.7 & 1.3 & \\
& & & {$[.00]$} & {$[.00]$} & & & {$[.00]$} & {$[.00]$} & & & {$[.02]$} & {$[.25]$} & \\
Corrupt & & 0.05 & & 0.04 & & 5.5 & & 3.7 & & 0.64 & & 0.53 & 0.24 \\
& & {$[.00]$} & & {$[.00]$} & & {$[.00]$} & & {$[.07]$} & & {$[.34]$} & & {$[.46]$} & {$[.00]$} \\
& & & & & & & & & & & & & \\
Adj. $R^{2}$ & 0.10 & 0.21 & 0.15 & 0.22 & 0.09 & 0.18 & 0.17 & 0.22 & 0.07 & 0.03 & 0.06 & 0.01 & 0.14 \\
Nb. obs. & 100 & 87 & 100 & 87 & 100 & 87 & 100 & 87 & 72 & 68 & 72 & 68 & 87 \\
\hline
\end{tabular}

where $D=\pi /(1+\pi)$ follows from Cukierman (1992); $D$ is a transformed inflation rate $(\pi)$ so as to reduce potential heteroskedasticity problems. ${ }^{57} S d \pi$ and $S d U$ refer to the standard deviation of inflation and unemployment, respectively. p-values in brackets.

As can be seen, the above regressions confirm the predictions of the model: both the level and the variability (standard deviation) of inflation are positively and significantly affected by the turnover of central bank governors, and also by the difference between governors' turnover and the frequency of elections (which, according to our model, better captures the true degree of independence of a central bank). Interestingly, this latter variable is significantly better at explaining the level and variability than the central bank governor tenure variable (see adjusted

\footnotetext{
${ }^{56}$ This view of the rents from office abstain from the "ego" rents that an officeholder might derive because of the sheer prestige/status of being in office. These are certainly important but difficult to quantify. Hence our focus on corruption.

${ }^{57}$ Note that, to avoid having our results being driven by hyperinflation episodes, observations where the level and variability of the inflation rate are above 100 percent have been dropped. Alternative thresholds do not noticeably change our results
} 
$R^{2}$ ). Controlling for corruption, which our theory predicts affects the incentive to delegate monetary policy, does not change these results. Finally, the last column shows that, as predicted, the

higher corruption within the political system, the lower the incentive to establish an independent central bank (as measured by TurnElec).

\section{Conclusion}

Why would an office-motivated politician spontaneously decide to delegate his monetary policy prerogative to an independent but accountable central bank? In this paper we have developed a theory of central bank independence that provides an answer to this question, and does so in a framework that is different from existing theories of CBI (which all rely on the presence of an inflation bias in monetary policy as the underlying reason for delegation). Our theory does not rely on the existence of such an inflation bias: all agents have the same (imperfect) information; no citizen is ever fooled, even to his own benefit.

The proposed rationale for delegating monetary policy to an independent central banker is that he is given a long term job contract; this, in turn, enables the central banker to commit more effort into the conduct of monetary policy than an elected politician could ever afford to. This extra effort translates, in expectations, in better forecasts and fewer policy mistakes, which increases social welfare.

We find that, when the conditions for delegation are satisfied, a politician's private incentive is to delegate monetary policy to a central bank that is both instrument and goal independent. Although instrument independence is welfare enhancing for society, goal independence is not (it benefits the current majority of the population at the expense of the future majority). A goal dependent central bank can however arise if the politician is constrained by a constitution requiring a supermajority of the population/parliament to agree on institutional changes.

The interests of our approach are the following. First, it is consistent with Alan Blinder's (1998) description of the rationale for delegating monetary policy to an independent agency, namely that "monetary policy, by its very nature, requires a long time horizon"; a key feature of our model. Second, our model is a possible answer to the critiques on the foundation of existing CBI theories: the existence of an inflation bias as a rationale for independence.

Third, our political agency framework offers a different view on the debate between goal and instrument independence. Scholars of central banking have repeatedly emphasized this difference (e.g., Debelle and Fischer (1994), Blinder (1998)), stressing that CBI and democracy are not antagonistic; Our model accords with this view (as does most of the contracting approach CBI literature). The advantage of our framework, we believe, is a contracting environment that better describes the types of incentives available in the public sector; whereas existing theories rely on explicit incentive contracts (financial rewards or penalties for achieving a target) in alleviating/eliminating the inflation bias and therefore providing a rationale for CBI, our approach relies on implicit incentives (i.e., concerns for you future career prospects). It is well known that explicit incentives are relatively low powered in public organizations but that implicit incentives 
play a prominent role (Wilson, 1989). We have also shown why goal independent central banks can emerge even though a goal dependent central bank leads to higher social welfare. ${ }^{60}$

Fourth, it enables us to address the endogeneity criticism highlighted by Posen (1993, 1995): namely, (1) that independent central banks reflect the preferences of society (independence can only occur, in our model, if an elected politician decides it is in society's (or at least the majority's) welfare; moreover, the central banker remains accountable to an elected representative); and (2) that the effectiveness of laws and institutions in providing for a truly independent central bank depends on the political support given to its goal(s).

Our alternative rationale for CBI could help explain why, in recent years, many economies have been actively increasing the independence of their central bank. According to our model, the sharp increase in the frequency of elections across the world during the 1990s compared to previous decades played a major role. Other key variables, despite being difficult to quantify, would be an increase in the complexity of conducting monetary policy, and a decrease in the rent that politicians derive from running monetary policy themselves.

\footnotetext{
${ }^{60}$ It increases the welfare of the politician (and those that share his preferences) that establishes the initial contract with the central banker.
} 


\section{A Mathematical Appendix}

\section{A.1 Proof that $\mathrm{c}$ is strictly positive}

First we show that

$$
\alpha-2 \beta>0
$$

First note that since the probability has to between 0 and 1 we have that

$$
\frac{1}{2}+\frac{1}{2} \theta_{G}+e_{1}+\beta e_{2}<1
$$

and that, using the equilibrium values for $e_{1}$ and $e_{2}$ under Delegation, we have

$$
\frac{1}{2}+\frac{1+\beta}{\alpha}+\frac{\beta}{\alpha}<1
$$

so that

$$
\frac{1+2 \beta}{\alpha}<\frac{1}{2}
$$

and

$$
2(1+2 \beta)<\alpha
$$

which gives

$$
\alpha-2 \beta>2(1+\beta)>0
$$

We prove that the coefficient $\gamma_{3}$ of $U^{D}=\gamma_{1}+\gamma_{2} \theta_{G}+\gamma_{3} \theta_{G}^{2}$ is greater than zero is strictly positive. The coefficient $\gamma$ is positive if

$$
\frac{\beta^{2}}{\alpha-2 \beta}+\frac{\beta^{3}}{(\alpha-2 \beta)^{2}}>\frac{1}{2} \alpha \frac{\beta^{2}}{(\alpha-2 \beta)^{2}}
$$

i.e., if

$$
\begin{aligned}
(\alpha-2 \beta) \beta^{2}+\beta^{3} & >\frac{1}{2} \alpha \beta^{2} \\
\alpha \beta^{2}-\beta^{3} & >\frac{1}{2} \alpha \beta^{2} \\
\alpha-\beta & >\frac{1}{2} \alpha \\
\frac{1}{2} \alpha-\beta & >0 \\
\alpha-2 \beta & >0
\end{aligned}
$$

which we know is positive by (45). 


\section{B References}

Alesina, A., and R. Gatti, 1995, "Independent Central Banks: Low Inflation at No Cost?" American Economic Review, Vol. 82, pp. 196-200.

Alesina, A., and G. Tabellini, 2003, "Bureaucrats or Politicians?," mimeo Harvard and Bocconi Universities, June.

Barro, R., 1973, "The Control of Politicians: An Economic Model," Public Choice, Vol. 14, pp. $19-42$.

Besley, T., and S. Coate, 2001, "Elected Versus Appointed Regulators: Theory and Evidence," forthcoming in the Journal of the European Economics Association.

Blinder, A., 1998, Central Banking in Theory and Practice, MIT Press, Cambridge.

Clarida, R., J. Gali, and M. Gertler, 1999, "The Science of Monetary Policy: A New Keynesian Perspective," Journal of Economic Literature, Vol. 37, pp. 1661-1707.

Cukierman, A., 1992, Central Bank Strategy, Credibility, and Independence: Theory and Evidence, MIT Press, Cambridge.

Debelle, G., and S. Fischer, 1994, "How Independent Should a Central Bank Be?", in J. Fuhrer, ed. Goals, Guidelines, and Constraints Facing Monetary Policymakers, Federal Reserve Bank of Boston Conference Series, No. 38.

Dewatripont, M, I. Jewitt, and J. Tirole, 1999, "The Economics of Career Concerns, Part II: Application to Missions and Accountability of Government Agencies," Review of Economic Studies, Vol. 66, pp. 199-217.

Drazen, A., 2001, “"'Laying Low” During Elections: Political Pressure and Monetary Accommodation" (unpublished; University of Maryland.)

— 2000, Political Economy in Macroeconomics, Princeton University Press, Princeton, NJ.

Eggertsson, G., 2003, "How to Fight Deflation in a Liquidity Trap: Committing to Being Irresponsible" IMF Working Paper, No. 03/64, Washington DC.

Eggertsson, G., and E. Le Borgne, 2003, "A Political Agency Theory of Central Bank Independence," IMF Working Paper, No. 03/144, Washington DC.

Ferejohn, J., 1986, "Incumbent Performance and Electoral Control," Public Choice, Vol. 50, pp. $5-26$. 
Fischer, S., 1995, "Central-Bank Independence Revisited," American Economic Review, Vol. 85, pp. 201-6.

Franzese, R.J., 1999, "Partially Independent Central Banks, Politically Responsive Governments, and Inflation," American Journal of Political Science, Vol. 43, No. 3.

Green, J., and N. Stokey, 1983, "Tournaments and Contracts," Journal of Political Economy, Vol. 91, pp. 349-64.

Holmström, B., 1999, "Managerial Incentive Problems: A Dynamic Perspective," Review of Economic Studies, Vol. 66, pp. 169-82. Originally, 1982, in Essays in Economics and Management in Honor of Lars Wahlbeck (Stockholm: Swedish School of Economics).

Lazear, E.P., and S. Rosen, 1981, "Rank-Order Tournaments as Optimum Labor Contracts," Journal of Political Economy, Vol. 89, pp. 841-64.

Le Borgne, E., and B. Lockwood, 2003, "Do Elections Always Motivate Incumbents? Experimentation vs. Career Concerns," IMF Working Paper No. 57/03, Washington DC.

— 2002, "Candidate Entry, Screening, and the Political Budget Cycle," IMF Working Paper No. 02/48, Washington DC.

Lin, X., 1999, "Central-Bank Independence, Economic Behavior, and Optimal Term Lengths: Comment," American Economic Review, Vol. 89, pp. 1056-62.

Lippi, F., 1998, "On Central Bank Independence and the Stability of Policy Targets," Scandinavian Journal of Economics, Vol. 89, pp. 841-64.

Lockwood, B., 1997, "State-Contingent Inflation Contracts and Unemployment Persistence," Journal of Money, Credit, and Banking, Vol. 29, pp. 286-99.

Maskin, E., and J. Tirole, 2004, "The Politician and the Judge: Accountability in Government," American Economic Review, forthcoming.

McCallum, B.T., 1995, "Two Fallacies Concerning Central-Bank Independence," American Economic Review, Papers and Proceedings, Vol. 85, pp. 207-11.

Muscatelli, A., 1998, "Optimal Inflation Contracts and Inflation Targets with Uncertain Central Bank Preferences: Accountability Through Independence," Economic Journal, Vol. 108, pp. $529-42$.

Persson, T., and G. Tabellini, 2000, Political Economics: Explaining Economic Policy, MIT Press, Cambridge, MA. 
— 1993, "Designing Institutions for Monetary Stability," Carnegie-Rochester Conference on Public Policy, Vol. 39, pp. 53-84.

Posen, A., 1995, "Declarations Are Not Enough: Financial Sector Sources of Central Bank Independence," in B. Bernanke and J. Rotemberg, eds. NBER Macroeconomics Annual, MIT Press, Cambridge, MA.

— 1993, "Why Central Bank Independence Does Not Cause Low Inflation: There is No Institutional Fix For Politics," in R. O'Brien, ed. Finance and the International Economy, Vol. 7, Oxford University Press, Oxford.

Prescott, E.C., 1972, "The Multiperiod Control Problem Under Uncertainty," Econometrica, Vol. 40, pp. 1043-58.

Rogoff, K. and A. Sibert (1988), "Elections and Macroeconomic Policy Cycles", Review of Economic Studies, Vol. 55, pp. 1-16.

Rogoff, K., 1985, "The Optimal Degree of Commitment to an Intermediate Monetary Target," Quarterly Journal of Economics, Vol. 100, pp. 1169-89.

Rotenberg, J. J., and M. Woodford, 1997, “An Optimization-Based Econometric Framework for the Calculation of Monetary Policy," NBER Macroeconomics Annual, Vol. 12, pp. 297-346.

Schellekens, P., 2002, "Caution and Conservatism in the Making of Monetary Policy," Journal of Money, Credit, and Banking, Vol. 34, pp. 160-77.

Svensson, L.E.O., 1997, "Optimal Inflation Target, 'Conservative' Central Banks, and Linear Inflation Contracts," American Economic Review, Vol. 87, pp. 98-114.

Vickers, J., 1998, "Inflation Targeting in Practice: The UK Experience," Bank of England Quarterly Bulletin, Vol. 38, pp. 368-75.

Waller, C.J., and C.E. Walsh, 1996, "Central-Bank Independence, Economic Behavior, and Optimal Term Lengths," American Economic Review, Vol. 86, pp. 1139-53.

Walsh, C.E., 1998, Monetary Theory and Policy, MIT Press, Cambridge, MA.

— , 1995, "Optimal Contracts for Central Bankers," American Economic Review, Vol. 85, pp. $150-67$.

Wilson, J.Q., 1989, Bureaucracy: What Government Agencies Do and Why They Do It, Basic Books, New York. 